\title{
Scenarios of Bioenergy Recovery from Organic Fraction of Residual Municipal Waste in the Marche Region (Italy)
}

\author{
Massimiliano Boccarossa ${ }^{1,2}$, Martina Di Addario ${ }^{3}$, Adele Folino ${ }^{3}$ and Fabio Tatàno $^{3, *(D)}$ \\ 1 Waste Register Section, ARPAM-Environmental Protection Agency of the Marche Region, \\ 61122 Pesaro, Italy; massimiliano.boccarossa@ambiente.marche.it \\ 2 Department of Industrial Chemistry "Toso Montanari", University of Bologna, 40126 Bologna, Italy \\ 3 Section ChEM-Chemistry, Environment, and Materials, DiSPeA-Department of Pure and Applied Sciences, \\ University of Urbino "Carlo Bo", 61029 Urbino, Italy; martina.di.addario@gmail.com (M.D.A.); \\ adelefolino@gmail.com (A.F.) \\ * Correspondence: fabio.tatano@uniurb.it
}

Citation: Boccarossa, M.; Di Addario, M.; Folino, A.; Tatàno, F. Scenarios of Bioenergy Recovery from Organic Fraction of Residual Municipal Waste in the Marche Region (Italy). Sustainability 2021, 13, 11462. https:// doi.org/10.3390/su132011462

Academic Editor: Isabella Pecorini

Received: 26 September 2021

Accepted: 11 October 2021

Published: 17 October 2021

Publisher's Note: MDPI stays neutral with regard to jurisdictional claims in published maps and institutional affiliations.

Copyright: (c) 2021 by the authors. Licensee MDPI, Basel, Switzerland. This article is an open access article distributed under the terms and conditions of the Creative Commons Attribution (CC BY) license (https:/ / creativecommons.org/licenses/by/ $4.0 /)$.

\begin{abstract}
In the Marche Region (Central Italy), the residual municipal waste (RMW) is commonly processed in mechanical biological treatment (MBT) systems. In these systems, following a first mechanical selection, the undersize organic fraction from RMW (us-OFRMW) undergoes a partial aerobic biological treatment before being landfilled as a biostabilised fraction (bios-OFRMW) without dedicated energy or material recovery. Alternative us-OFRMW management scenarios have been elaborated for this region, at both present (reference year 2019) and future (reference year 2035) time bases. In the first scenario, the potential bioenergy recovery through anaerobic digestion (AD) from the us-OFRMW was evaluated. The second scenario aimed at evaluating the residual methane generation expected from the bios-OFRMW once landfilled, thus contributing also to the potential environmental impact connected with landfill gas (LFG) diffuse emissions from the regional landfills. The diversion to $\mathrm{AD}$, at the present time, would allow a potential bioenergy recovery from the us-OFRMW equal to $4.35 \mathrm{MW}_{\mathrm{el}}$, while the alternative scenario involves greenhouse gas (GHG) emissions equal to $195 \mathrm{~kg} \mathrm{CO} 2$ eq. per ton of deposited bios-OFRMW. In the future, the decreased amount of the us-OFRMW addressed to $\mathrm{AD}$ would still contribute with a potential bioenergy recovery of $3.47 \mathrm{MW}_{\mathrm{el}}$.
\end{abstract}

Keywords: anaerobic digestion; bioenergy recovery; biostabilisation; environmental planning; landfill; mechanical biological treatment; methane emission; organic fraction; region; residual municipal waste

\section{Introduction}

One of the main issues related to municipal waste (MW) is the management of the related organic fraction (OFMW). In Italy, the generation of MW in 2019 was about 30.1 million ton [1]. In the same year, the separately collected MW (sc-MW) accounted for $61.3 \%$ of the totally generated MW [1]. The OFMW, representing a level of about $35.4 \%$ in the composition of the generated MW (as the Italian average estimate in the multiyear period 2009-2019), is mainly diverted as a separately collected stream (sc-OFMW), accounting in Italy for 39.5\% of the total amount of sc-MW in 2019 [1]. However, a non-negligible amount of organic fraction still remains in the residual municipal waste (RMW) stream [2], that accounted in Italy for about 11.6 million ton in 2019 [1]. The direct disposal of organic waste in landfills can generate potential environmental impacts on the air, soil, and water through the uncontrolled release of biogas and leachate [3].

At least at the European level, to prevent or reduce the potential environmental impacts from landfills, the mechanical biological treatment (MBT) concept is playing a key role in the preliminary treatment of the organic fraction of RMW (OFRMW) prior to landfilling [4,5]. Particularly, in the common MBT technological variation targeted at biostabilising 
the OFRMW, usually referred to as biostabilisation MBT, a mechanical selection is typically performed first on the RMW to obtain (as an intermediate output) an undersize stream rich in putrescible organic matter (us-OFRMW), which is further partially biodegraded (mainly with aerobic systems) to produce a stabilised organic output destined for landfilling [2,6-9]. However, a recent study found that the aerobically biostabilised organic output (bios-OFRMW), produced from the aerobic biostabilisation MBT, still presents a residual biochemical methane potential (BMP) [10]. Since the bios-OFRMW is generally destined for landfilling, this means that it may still contribute to landfill methane generation, but also to greenhouse gas (GHG) diffuse emissions, as the methane produced in landfills is not totally conveyed by the implemented landfill gas (LFG) collection and extraction systems [11]. Although aerobic biostabilisation MBT plants represent well established systems to manage the RMW, they are expected to be energy consuming (in particular, to guarantee the forced aeration in the aerobic phase [12]); moreover, they do not allow the recovery of fuels (in the prevailing situation, at least in Italy, of the mechanically separated, oversize fraction of RMW—os-RMW—similarly addressed to landfilling [1]) or other valuable organic material recovery (compared, for instance, to compost obtained from the aerobic treatment of the sc-OFMW). Thus, under the important role that the overall biowaste stream can play in the transition towards a circular economy [13], the potential diversion of the us-OFRMW to an anaerobic biological treatment step, still within the MBT concept, could represent a valuable and environmentally friendly strategy. In fact, the methane-rich biogas generated by the anaerobic digestion (AD) of biomass resources and organic waste constitutes a renewable bioenergy that can displace fossil-fuel-based energy production [13,14].

Given the above considerations, this study aimed at elaborating and comparing alternative scenarios for bioenergy recovery through anaerobic processes from the OFRMW in the Marche Region (Central Italy, Adriatic Sea side). The first scenario, called

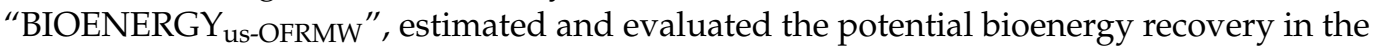
case of an anaerobic biological treatment step of the us-OFRMW within the MBT concept, as an alternative to the current aerobic step. The second scenario, called "BIOENERGYIMPACT $_{\text {bios-OFRMW", focused on the evaluation of the potential residual methane genera- }}$ tion expected from the disposal of the bios-OFRMW at the regional landfills in case the us-OFRMW continues to be treated aerobically in MBT systems. Moreover, two time bases were considered for the development of the scenarios: present (reference year 2019) and future (reference year 2035). The main objective of this study was to assess the extent to which the potential anaerobic biological treatment step within the MBT concept could be advantageous as bioenergy recovery from the us-OFRMW generated (and generable) in the Marche Region or, conversely, the extent to which the actual and unchanged management approach could negatively contribute to the potential environmental impact connected with GHG diffuse emissions from the landfilling of aerobically treated us-OFRMW.

\section{Methodology}

\subsection{Synthetic Overview on MW Management in the Marche Region}

The Marche Region is composed of five provincial territories (hereinafter identified as PT1-PT5: Figure 1), with a total population of about 1,525,000 inhabitants in 2019 [15] and an extension of about $9400 \mathrm{~km}^{2}$ [16]. The MW generation in the Marche Region in 2019 was equal to 792,645 ton, with a corresponding per capita MW generation of $520 \mathrm{~kg}$ person $^{-1}$ year $^{-1}$ [15]. The obtained regional level of sc-MW was equal to $70.5 \%$ in 2019 [15]. Referring to the management of sc-OFMW in 2019, an amount of 99,590 ton was reported to be treated in composting plants located in the regional territory, while a further amount of 97,974 ton was reported to be addressed to recovery facilities located outside the Marche Region [1]. No AD or waste-to-energy plants for MW are operated in the regional territory [1]. The resulting RMW, identified by the European Waste Code (EWC) 200301 [17], is addressed to no. 5 aerobic biostabilisation MBT systems (Figure 1). Particularly, each provincial territory from PT2 to PT5 is provided by an aerobic biostabilisation MBT plant whose main final material outputs, i.e., the bios-OFRMW (identified by the EWC 1905 
03 [17]) and the os-RMW (identified by the EWC 191212 [17]), are both disposed of at a pertaining controlled landfill $[1,15]$. Concerning instead the provincial territory PT1, the implemented complementary aerobic biostabilisation MBT system comprises no. 2 mechanical (selection) treatment (MT) steps, located in the coastal districts, whose generated us-OFRMW streams (identified by the EWC 190501 [17]) are addressed to the aerobic biological treatment phase of the complete MBT plant located in the inland district: similarly to the other provincial territories, the generated bios-OFRMW and os-RMW are disposed of at pertaining controlled landfills $[1,15]$. Table S1 of the Supplementary Material reports representative characteristics of the aerobic biostabilisation MBT systems located in the Marche Region. A synthetic representation of the overall MW management in the Marche Region is provided in Figure S1 of the Supplementary Material.

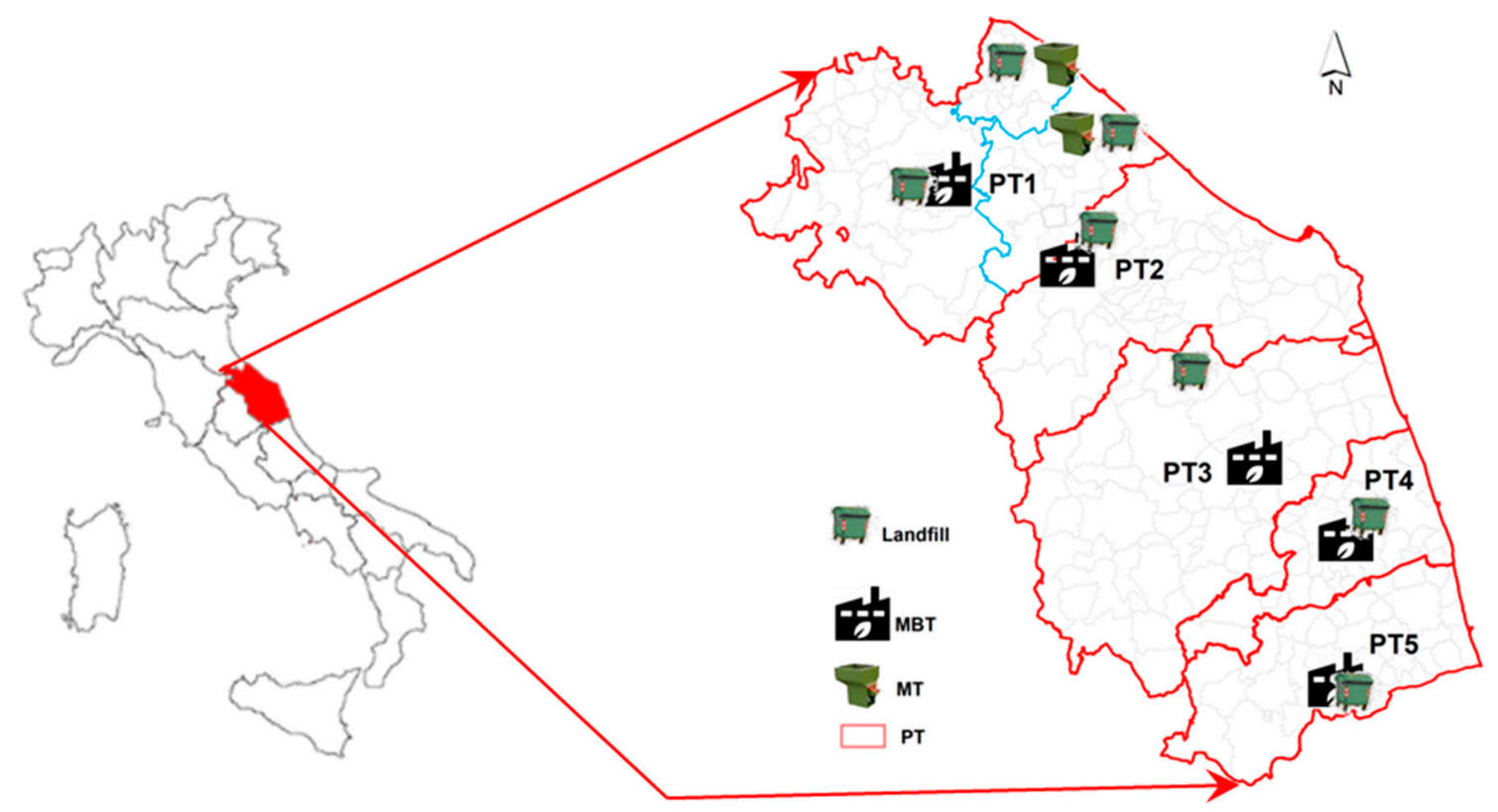

Figure 1. Overview on the Italian division in regional territories with detail (in red) of the Marche Region (left). The enlarged map (right) shows the provincial territories (PTs) of the Marche Region and the location of the respective MBT/MT and landfill facilities (status at the reference year 2019) (additional legend for PT1: blue line = disaggregation into two coastal districts and one inland district).

\subsection{Derivation of the Mass Balances of the Provincial MBT Systems}

The mass balance of each provincial aerobic biostabilisation MBT system was derived based on the collection and elaboration of the respective operational data and the actual configurations of the systems (see Table S1 of the Supplementary Material). The input was given by the received RMW, while the following final outputs were typical (Figure 2): os-RMW; bios-OFRMW; possibly metal (identified by the EWC 191202 [17]) from magnetic separation; possibly leachate or aqueous liquid waste (identified by the EWC 190703 or 16 1002 [17]) from the aerobic biological treatment step; and process losses. Concerning the intermediate output represented by the targeted us-OFRMW, the resulting percentage by mass (\%us-OFRMW) was derived based on the following expression:

$$
\text { \%us-OFRMW = } 100-(\% \text { os-RMW + \%metal })
$$

where \%os-RMW and \%metal represent the percentages by mass of the final outputs os-RMW and metal, respectively. 


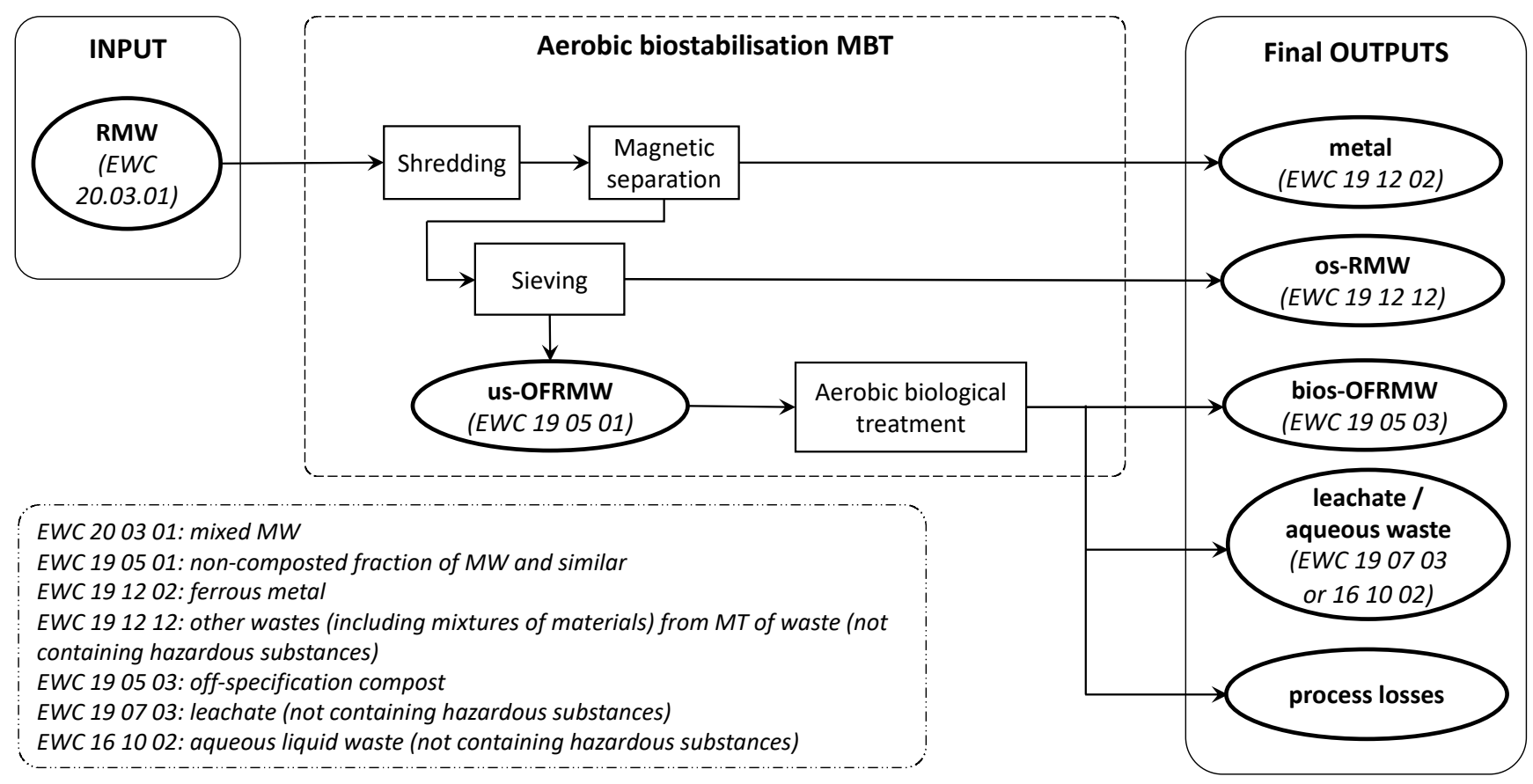

Figure 2. Typical aerobic biostabilisation MBT system in the Marche Region: flow chart and mass balance.

\subsection{Characterisation of the RMW, us-OFRMW, and bios-OFRMW}

For the qualitative characterisation of the RMW, compositional analyses were conducted on samples of the RMW addressed to the respective provincial aerobic biostabilisation MBT systems in the Marche Region. These analyses were performed in accordance with the sequential procedure (consisting of the heaping and removal of possible bulky materials, quartering, screening, manual sorting, and weighing) adopted by the Environmental Protection Agency of the Marche Region [18] and summarised in Table S2 of the Supplementary Material. In this study, the considered material fractions were diaper, glass, metal (assumed as the aggregation of pertaining packaging and other metal), organic (OFRMW, assumed as the aggregation of pertaining green waste, kitchen waste, and fines [8,19]), paper/cardboard (assumed as the aggregation of pertaining paper and cardboard), plastic (assumed as the aggregation of pertaining packaging and other plastic), textile, wood (assumed as the aggregation of pertaining packaging and other wood), and other (assumed as the aggregation of inert, hazardous waste, waste electrical and electronic equipment, and residue from sorting).

Samples of us-OFRMW (from the coastal districts in PT1 and the other provincial territories from PT2 to PT5) and bios-OFRMW (from all the provincial territories) were characterised in terms of moisture, total solids (TS), volatile solids (VS), total Kjeldahl nitrogen (TKN), total ammoniacal nitrogen (TAN), total phosphorus (TP), total potassium $(\mathrm{TK})$, and heavy metals $(\mathrm{Cd}, \mathrm{Cr}, \mathrm{Cu}, \mathrm{Ni}, \mathrm{Pb}$, and $\mathrm{Zn})$. The adopted analytical procedures are summarised in Section 2.6.

\subsection{Development of the BIOENERGY $Y_{\text {us-OFRMW Scenario }}$}

The BIOENERGY $Y_{\text {us-OFRMW }}$ scenario aimed at evaluating the potential bioenergy recovery through AD from the us-OFRMW in the Marche Region (Figure 3, left-down), as an alternative to the current aerobic biological treatment step within the implemented MBT concept (see Figure S1 of the Supplementary Material). 


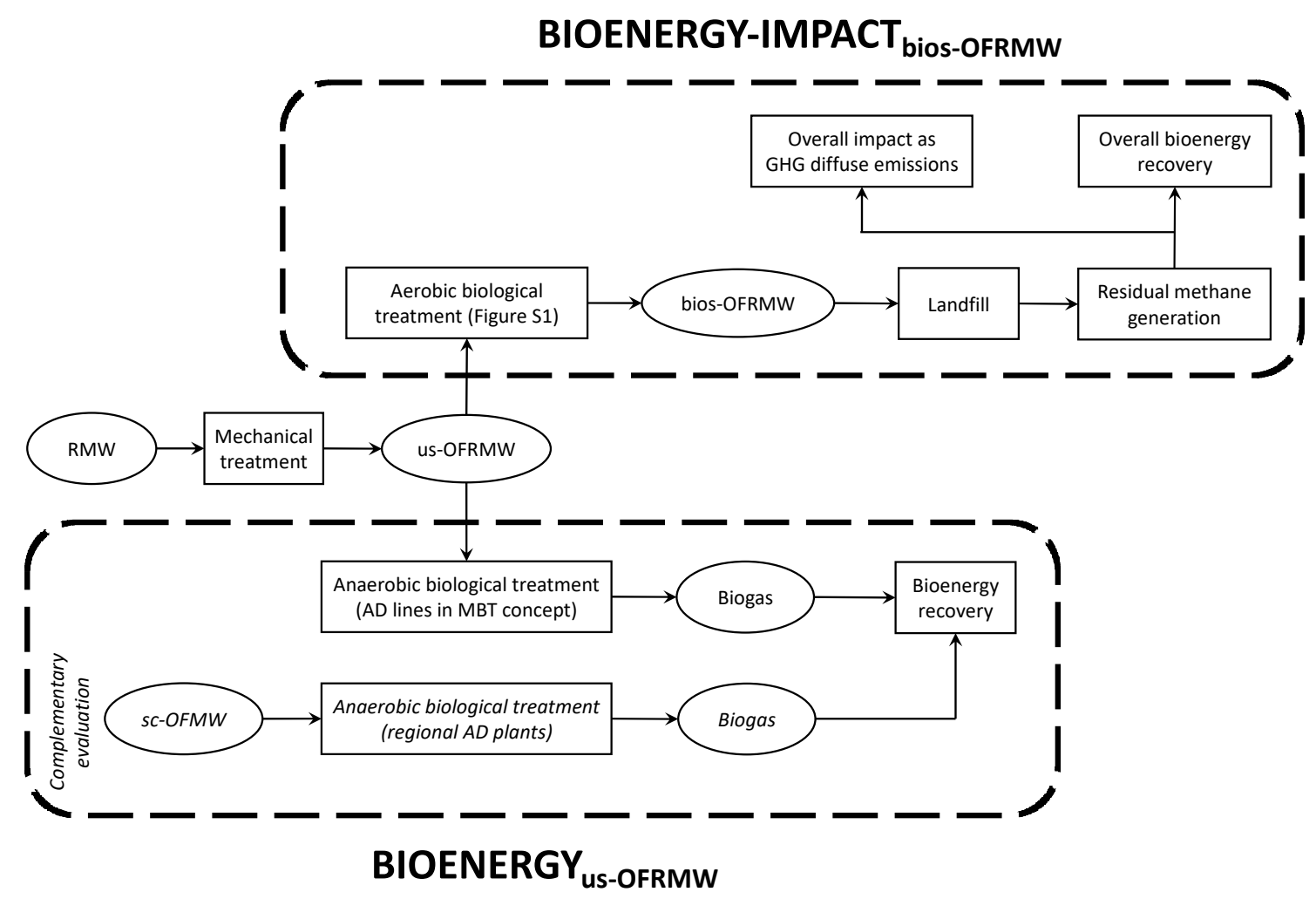

Figure 3. Schematisation of the alternative scenarios: BIOENERGY us-OFRMW (left-down, dotted line box) and BIOENERGYIMPACT $_{\text {bios-OFRMW }}$ (right-up, dotted line box).

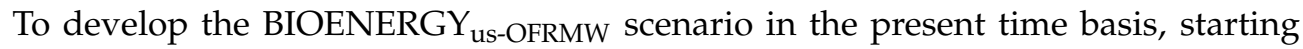
from the amounts of RMW processed by each provincial MBT system at the reference year 2019 and the related mass balances (see Section 2.2), it was possible to determine the resulting amounts of us-OFRMW produced by each provincial territory. Consequently, the estimation of the biomethane production expected through AD from the us-OFRMW was based on the initial assumption of a BMP of $445.6 \mathrm{Nm}^{3} \mathrm{CH}_{4}$ ton $\mathrm{VS}^{-1}$, obtained in a previous experimental study [10] as representative of the us-OFRMW from the MT step located in one coastal district of provincial territory PT1 (see Figure 1). Moreover, by knowing the VS and TS contents of the us-OFRMW samples collected from the remaining coastal district in PT1 and the provincial territories from PT2 to PT5 (see Section 2.3), the assumed BMP per VS unit was adapted to the profile of us-OFRMW produced by each provincial territory to derive a pertaining BMP per fresh matter (FM) unit.

Given the resulting estimate of biomethane production in each provincial territory, the corresponding gross electrical energy produced by the recovered biomethane was calculated by assuming a methane lower heating value equal to $36 \mathrm{MJ} \mathrm{Nm}^{-3}$ and an electrical efficiency equal to $38 \%[20,21]$. The related electrical power (i.e., the parameter used to estimate the size of a feasible AD line) was obtained by dividing the gross electrical energy by the yearly working hours of the AD line (assumed to be equal to $8200 \mathrm{~h}$ ) [20]. The net electrical energy, to be fed into the electricity grid [22], was derived by assuming an overall consumption to operate the $\mathrm{AD}$ line and run the gas engine equal to a proportion of $9.5 \%$ of the produced gross electricity, determined as the average value of the derivable range of $7-12 \%$ for small-scale and large-scale biogas plants [23]. In the combined heat and power (CHP) configuration, the gross $\mathrm{CHP}$ energy was determined by assuming a total energy efficiency equal to $82.5 \%$ as the average value of the reported range of $80-85 \%$ [24].

Regarding the future time basis, 2035 was chosen as the reference year, in line with its consideration as the farthermost targeted year by the representative European framework waste legislation as amended by directive 2018/851 [25], related to the European circular 
economy strategy. The following assumptions were made to estimate the amounts of sc-OFMW and us-OFRMW that will be produced in the Marche Region at the reference year 2035:

- $\quad$ Per capita MW generation of $472.1 \mathrm{~kg}$ person $^{-1}$ year $^{-1}$ as the objective of reducing the generation of waste set by the Marche's regional waste management plan [26].

- $\quad$ Regional population of 1,474,769 inhabitants, officially estimated (as the forecast median scenario) by the Italian National Institute of Statistics [27].

- $\quad$ Percentage of sc-OFMW set at $43.7 \%$ of the total regional amount of sc-MW, determined as the mean value from 2012 to 2019 .

- $\quad$ Percentage of us-OFRMW (related to the total regional amount of RMW) determined as the mean from the mass balances of the provincial MBT systems (see Section 2.2).

- $\quad$ Estimate of the level of sc-MW based on the fitting procedure of the available regional levels from 2001 to 2019 [15,28] with a modified Gompertz modelling [29] purposely adapted with the following equation:

$\%$ scMW $=\left(\% s c M W_{\max }-11.9\right) \exp \left\{-\exp \left[\frac{\mathrm{R} \cdot \mathrm{e}}{\left(\% \mathrm{scMW}_{\max }-11.9\right)}(\lambda-\mathrm{t})+1\right]\right\}+11.9$

where \%scMW is the level of sc-MW in the Marche Region at year $t, \% s c M W_{\max }$ is the expected upper horizontal asymptote (set at $74.7 \%$, as a reference based on the maximum level reached by the most virtuous Italian region in 2019 [1]), $\mathrm{R}$ is the maximum increasing rate of \%scMW, e is the Neper number, $\lambda$ is the lag time, and 11.9 represents the resulting $\%$ scMW in the Marche Region at the selected initial year, 2001 [28].

By comparing the assumed objective of per capita MW generation in 2035 to the resulting means from 2015 to 2019 in the Marche Region (equal to $526.0 \mathrm{~kg}_{\text {person }}{ }^{-1}$ year $^{-1}$ ) and in Central Italy (equal to $544.8 \mathrm{~kg}_{\text {person }}^{-1}$ year $^{-1}$ ) [1], the expected relative decreases (calculated as [( mean $_{2015-2019}$ - objective 2035$\left.\left.) /\left(\operatorname{mean}_{2015-2019}\right)\right] * 100\right)$ would be equal to 10 and $13 \%$, respectively, representing a desirable effort on the waste prevention that is required by the mentioned directive 2018/851 [25]. In the future time basis, the representative BMP per FM unit for the us-OFRMW at the regional level was assumed as the resulting mean of the respective BMPs per FM unit derived for each provincial territory.

As a complementary evaluation of the overall potential bioenergy recovery from the whole OFMW, the additional option of addressing the sc-OFMW to potential regional

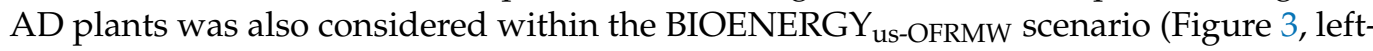
down). In this perspective, the following assumptions were made for the sc-OFMW: a BMP of $445 \mathrm{Nm}^{3} \mathrm{CH}_{4}$ ton $\mathrm{VS}^{-1}$, a TS content of $22.5 \% \mathrm{FM}$, and a VS content of $88.2 \%$ TS as the means of the ranges of $401-489 \mathrm{Nm}^{3} \mathrm{CH}_{4}$ ton $\mathrm{VS}^{-1}, 20-25 \% \mathrm{FM}$, and 85-91.44\% TS, respectively, derivable for separately collected and source-sorted organic waste from literature indications $[30,31]$.

\subsection{Development of the BIOENERGY-IMPACT bios-OFRMW $_{\text {Scenario }}$}

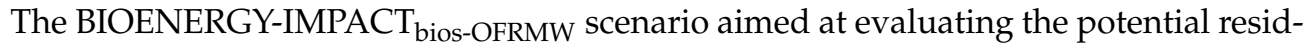
ual methane generation and GHG diffuse emissions expected from the bios-OFRMW disposed of at the regional landfills (Figure 3, right-up), in the case that the us-OFRMW continues to be treated aerobically in the existing MBT systems located in the Marche Region (see Figure 1 and Supplementary Material Figure S1).

For the present time basis (reference year 2019), the annual amounts of bios-OFRMW destined for landfilling in the provincial territories were obtained based on the mass balances of the provincial MBT systems (see Section 2.2). The potential residual methane generation, intended as the total (cumulative) production from the yearly deposited biosOFRMW that is expected to be approached exponentially during the landfill lifetime [32,33], was derived starting from a considered BMP of $143.4 \mathrm{Nm}^{3} \mathrm{CH}_{4}$ ton VS ${ }^{-1}$, obtained in a previous experimental study [10] performed on a sample of bios-OFRMW representative of the provincial territory PT1 in the Marche Region (see Figure 1). Based on the resulting VS and TS contents of the bios-OFRMW samples collected from the provincial territories 
(see Section 2.3), the assumed BMP per VS unit was adapted to the profile of bios-OFRMW produced by each provincial territory to derive a pertaining BMP per FM unit.

While all the biomethane produced by the us-OFRMW in the previous scenario is destined to energy recovery, in this alternative scenario the residual methane generation from deposited bios-OFRMW is mainly recovered energetically but partly represents a potential environmental impact in terms of diffuse GHG emissions (Figure 3, right-up). In particular, a volumetric methane extraction proportion of $79.2 \%$ and a complementary volumetric methane diffuse emission incidence of $20.8 \%$ were assumed, as derived from a multiyear (2007-2016) LFG emission monitoring study with the static, non-stationary chamber approach $[11,34]$ performed at one coastal landfill located in provincial territory PTI of the Marche Region (see Figure 1). To derive the overall gross electrical energy expected from the on-site conversion of the recovered LFG, the gas engine electrical efficiency was assumed to be equal to 37\% [35]. To account for the methane component in the emitted LFG as overall GHG emission, the respective global warming potential (GWP), over a 100-year time horizon, was set to 28 (without inclusion of climate-carbon feedback) [36].

To estimate the bios-OFRMW production expected at the regional level in the future time basis (reference year 2035), an average mass balance of the regional MBT systems (see Section 2.2) was considered. In the future time basis, the representative BMP per FM unit for the bios-OFRMW at the regional level was assumed as the resulting mean of the respective BMPs per FM unit derived for each provincial territory.

\subsection{Analytical Procedures}

The moisture and TS contents were determined by drying at $105^{\circ} \mathrm{C}$, while the VS content was determined by loss-on-ignition at $550^{\circ} \mathrm{C}$. The TKN and TAN contents were determined following the analytical method established for wastewater sludge [37]. The TP content was determined via inductively coupled plasma optical emission spectrometry [38,39]. The TK and heavy metal contents were determined through a pretreatment based on microwave digestion [38], followed by an analysis with inductively coupled plasma mass spectrometry [40].

\section{Results}

\subsection{Mass Balances of the Provincial MBT Systems}

Table 1 shows the resulting mass balances of the provincial aerobic biostabilisation MBT systems located in the Marche Region. Concerning the final outputs in each provincial MBT system, the prevailing component was represented by the os-RMW, followed by the targeted bios-OFRMW.

Table 1. Resulting mass balances of the provincial aerobic biostabilisation MBT systems in the Marche Region and related regional means.

\begin{tabular}{ccccccc}
\hline Output & PT1 & PT2 & PT3 & PT4 & PT5 & Regional Mean \\
\hline os-RMW (\% RMW) & 78.1 & 61.0 & 69.1 & 64.6 & 64.0 & 67.36 \\
metal (\% RMW) & 0.0 & 1.5 & 0.03 & 0.1 & 0.3 & 0.39 \\
bios-OFRMW (\% RMW) & 13.3 & 28.1 & 25.4 & 27.9 & 25.5 & 24.0 \\
leachate/aqueous liquid waste (\% RMW) & 0.0 & 0.0 & 3.02 & 0.0 & 1.1 & 0.8 \\
process losses (\% RMW) & 8.6 & 9.4 & 2.45 & 7.4 & 9.1 & 7.4 \\
total (\% RMW) & 100 & 100 & 100 & 100 & 100 & 100 \\
\hline us-OFRMW (\% RMW) & 21.9 & 37.5 & 30.9 & 35.3 & 35.7 & 32.3 \\
\hline
\end{tabular}

Interestingly, the resulting levels of the final output represented by the os-RMW and the intermediate output represented by the targeted us-OFRMW were evaluated in the association with the screen size of sieving in the MT step of the respective provincial MBT systems. In particular, as illustrated in Figure 4, a strong inverse correlation in the association of the os-RWM with the screen size of sieving was revealed by the obtained correlation coefficient ( $\mathrm{r}$ ) value of -0.826 ; concurrently, a strong positive correlation in the association of the us-OFRMW with the screen size of sieving was revealed by the 
obtained $\mathrm{r}$ value of 0.821 [41]. Regarding the mutual comparison of the MT steps in PT1 and PT3 (with resulting higher os-RMW and lower us-OFRMW levels, respectively, in PT1 than in PT3: see Figure 4 and Table 1), it should be observed that the sieving in PT3, although characterised by a lower screen size $(45 \mathrm{~mm})$, was preceded by a double system of shredding (see Table S1 of the Supplementary Material). Instead, only a bland shredding preceded the sieving in PT1 presenting a higher screen size $(48 \mathrm{~mm}$, as the representative mean from the coastal and inland districts) (see Table S1 of the Supplementary Material).

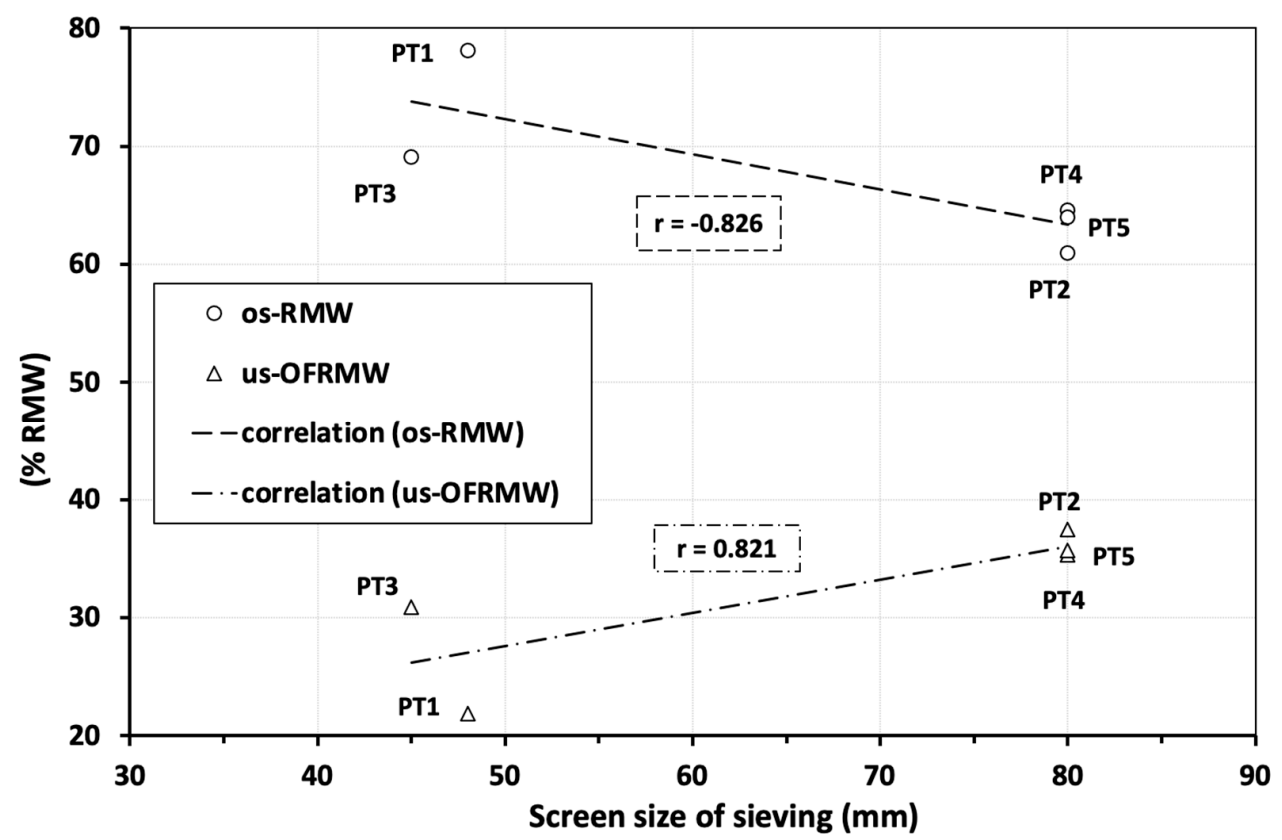

Figure 4. Mass balances of the provincial aerobic biostabilisation MBT systems in the Marche Region: resulting levels of os-RMW and us-OFRMW versus corresponding screen sizes of the sieving step.

Finally, the resulting regional means of $32.3 \%$ for us-OFRMW and $24.0 \%$ for biosOFRMW in Table 1 were assumed in the elaboration of the future time basis of the BIOENERGY $_{\text {us-OFRMW }}$ and BIOENERGY-IMPACT bios-OFRMW $_{\text {scenarios, respectively (see }}$ Sections 2.4 and 2.5).

\subsection{Representative Compositional Characteristics of the RMW}

Figure 5 displays the resulting compositions of the RMW in the provincial territories of the Marche Region and as a regional mean. On the regional average (Figure 5f), the overall organic component represented the highest compositional level (equal to 30.8\%) in the RMW: at the individual provincial territories, the incidence of the overall organic component in the RWM ranged from $21.0 \%$ in PT4 (i.e., the least populated provincial territory in the Marche Region [1]: Figure 5d) to $43.0 \%$ in PT2 (i.e., the most populated provincial territory in the Marche Region [1]: Figure 5b). For the remaining fractions, the resulting incidences in the RMW were, on the regional average (Figure 5f), in the following decreasing order: plastic (ranging from $10.0 \%$ in PT4 to $21.5 \%$ in PT5, with a regional mean of $16.6 \%$ ), diaper (ranging from $7.5 \%$ in PT1 to $29.3 \%$ in PT4, with a regional mean of $13.6 \%$ ), paper/cardboard (ranging from $7.1 \%$ in PT4 to $18.7 \%$ in PT3, with a regional mean of $12.7 \%$ ), other (ranging from $1.0 \%$ in PT1 to $25.5 \%$ in PT4, with a regional mean of $11.7 \%$ ), textile (ranging from $3.8 \%$ in PT3 to $16.0 \%$ in PT2, with a regional mean of $7.3 \%$ ), metal (ranging from $1.5 \%$ in PT4 to $5.0 \%$ in PT5, with a regional mean of $3.4 \%$ ), wood (ranging from $0.8 \%$ in PT4 to $4.4 \%$ in PT3, with a regional mean of $2.5 \%$ ), and glass (ranging from $0.4 \%$ in PT2-PT4 to $2.3 \%$ in PT1, with a regional mean of $1.4 \%$ ). 


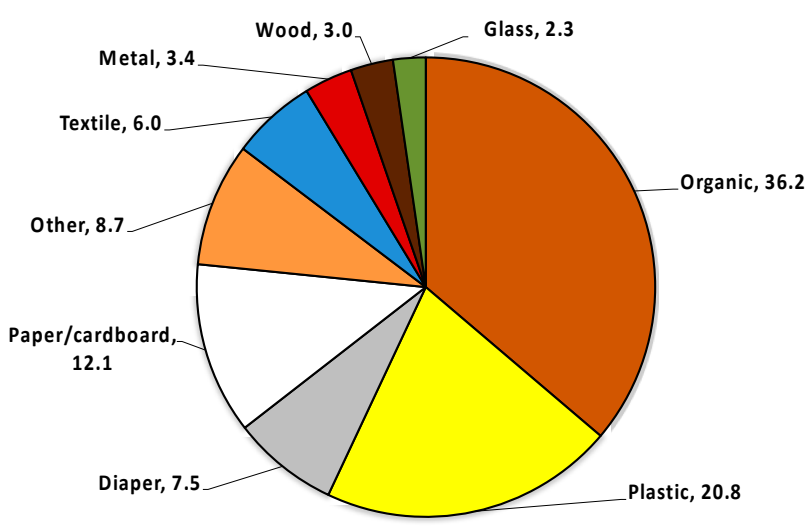

(a, PT1)

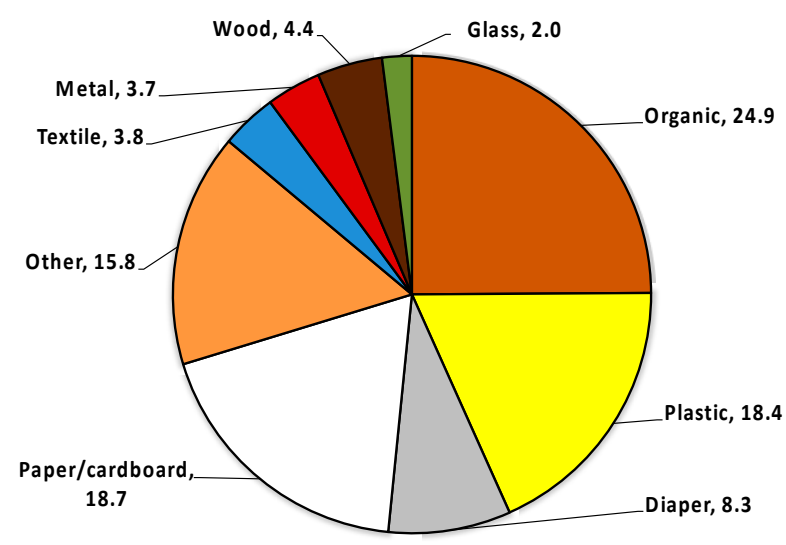

(c, PT3)

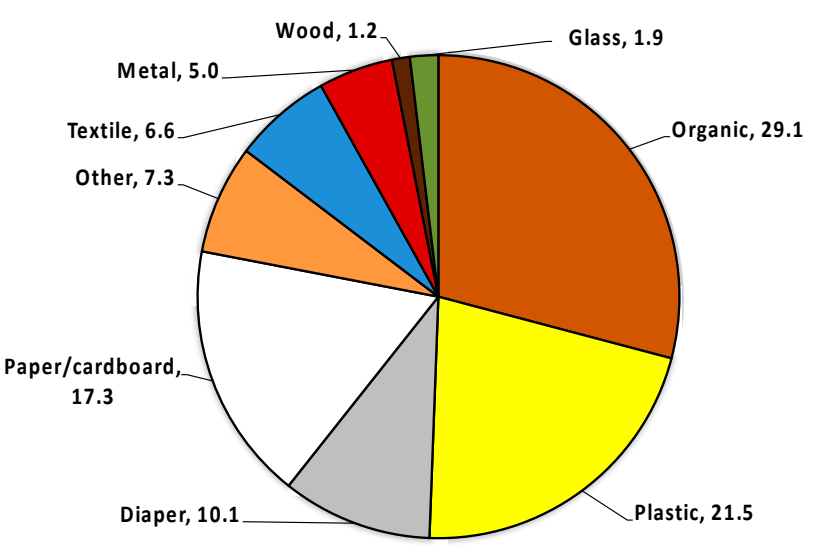

(e, PT5)

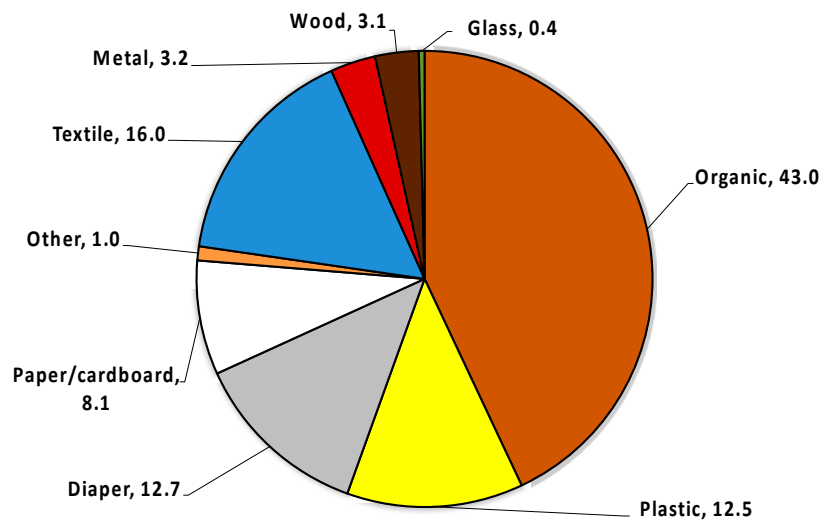

(b, PT2)

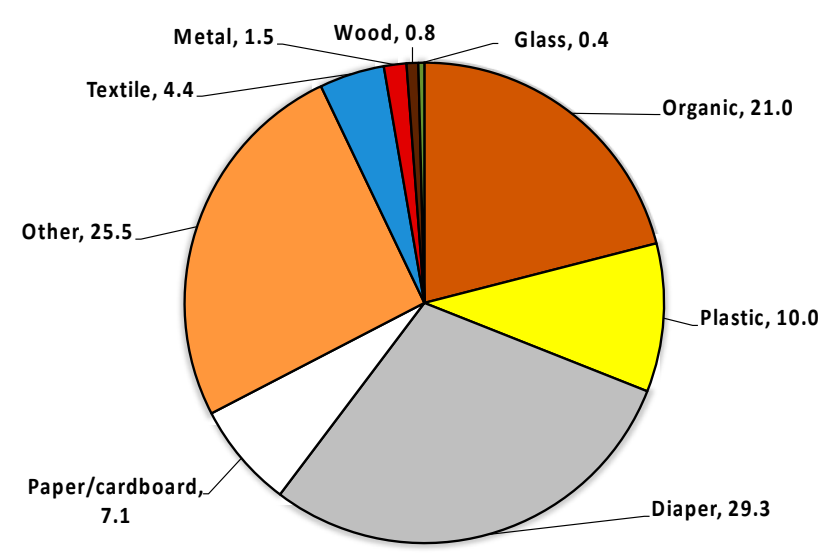

(d, PT4)

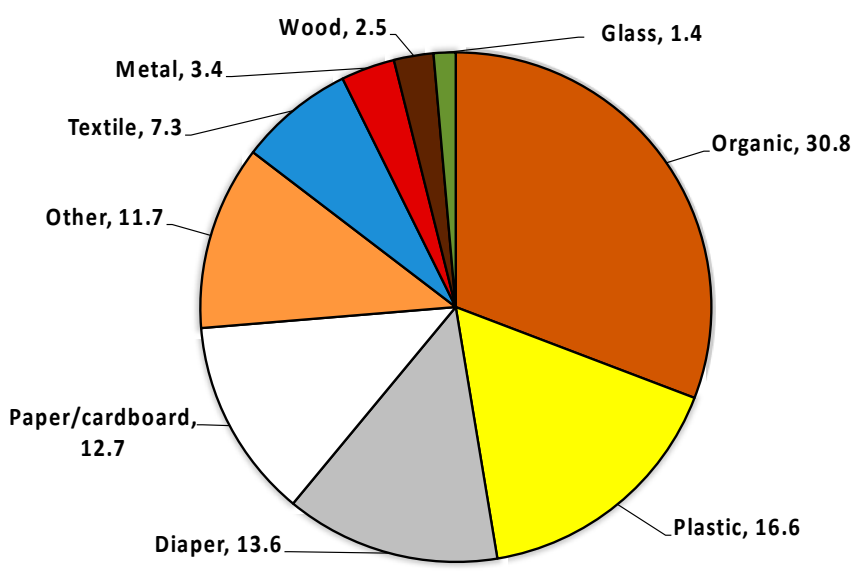

(f, Marche Region)

Figure 5. Resulting compositions of the RMW in the provincial territories (PTs, $(\mathbf{a}-\mathbf{e})$ ) of the Marche Region and as a regional mean (f). 


\subsection{Representative Physico-Chemical Characteristics and BMPs of the us-OFRMW and bios-OFRMW}

The analytical data on the physico-chemical characteristics of the investigated usOFRMW and bios-OFRMW from the provincial territories in the Marche Region are reported in Tables 2 and 3, respectively.

Table 2. Representative physico-chemical characteristics of the us-OFRMW from the provincial territories in the Marche Region.

\begin{tabular}{|c|c|c|c|c|c|}
\hline Provincial Territory & PT1 $^{3}$ & PT2 & PT3 & PT4 & PT5 \\
\hline Moisture (\% FM) ${ }^{1}$ & 42.66 & 36.45 & 41.41 & 38.42 & 51.01 \\
\hline TS (\% FM) ${ }^{1}$ & 57.34 & 63.55 & 58.59 & 61.58 & 48.99 \\
\hline VS (\% TS) ${ }^{1}$ & 46.33 & 49.55 & 61.23 & 41.97 & 55.80 \\
\hline $\mathrm{TKN}\left(\mathrm{g} \mathrm{kg} \mathrm{TS}^{-1}\right)^{1}$ & 7.74 & 22.97 & 17.07 & 23.55 & 8.37 \\
\hline TAN $\left(\mathrm{g} \mathrm{kg} \mathrm{TS}^{-1}\right)^{1}$ & 0.75 & 0.42 & 1.03 & 2.24 & 1.32 \\
\hline $\mathrm{TP}\left(\mathrm{g} \mathrm{kg} \mathrm{TS}^{-1}\right)^{1}$ & 2.01 & 1.04 & 0.81 & 6.22 & 0.94 \\
\hline $\mathrm{TK}\left(\mathrm{g} \mathrm{kg} \mathrm{TS}^{-1}\right)^{1}$ & 3.84 & 1.50 & 4.25 & 6.52 & 2.83 \\
\hline $\mathrm{Cd}\left(\mathrm{mg} \mathrm{kg} \mathrm{TS}^{-1}\right)^{1}$ & 0.16 & 0.00 & 0.00 & 0.00 & 0.00 \\
\hline $\mathrm{Cr}\left(\mathrm{mg} \mathrm{kg} \mathrm{TS}^{-1}\right)$ & $13.94^{1}$ & $73.43^{1}$ & $34.14^{2}$ & $16.24^{2}$ & $0.00^{1}$ \\
\hline $\mathrm{Cu}\left(\mathrm{mg} \mathrm{kg} \mathrm{TS}^{-1}\right)$ & $40.80^{1}$ & $136.38^{1}$ & $2651.19^{1}$ & $81.20^{2}$ & $81.65^{2}$ \\
\hline $\mathrm{Ni}\left(\mathrm{mg} \mathrm{kg} \mathrm{TS}^{-1}\right)$ & $5.39^{1}$ & $15.74^{2}$ & $17.07^{2}$ & $16.24^{2}$ & $0.00^{1}$ \\
\hline $\mathrm{Pb}\left(\mathrm{mg} \mathrm{kg} \mathrm{TS}^{-1}\right)$ & $5.44^{1}$ & $31.47^{2}$ & $22.76^{1}$ & $162.39^{2}$ & $0.00^{1}$ \\
\hline $\mathrm{Zn}\left(\mathrm{mg} \mathrm{kg} \mathrm{TS}^{-1}\right)$ & $417.97^{1}$ & $3252.03^{1}$ & $1018.38^{1}$ & $1553.53^{1}$ & $571.55^{2}$ \\
\hline
\end{tabular}

${ }^{1}$ Mean of three determinations; ${ }^{2}$ Individual determination; ${ }^{3}$ Average condition from the resulting characteristics of the us-OFRMW obtained from the MT steps located in the coastal districts (see Figure 1).

Table 3. Representative physico-chemical characteristics of the bios-OFRMW from the provincial territories in the Marche Region.

\begin{tabular}{|c|c|c|c|c|c|}
\hline Provincial Territory & PT1 & PT2 & PT3 & PT4 & PT5 \\
\hline Moisture $\left(\%\right.$ FM) ${ }^{1}$ & 25.19 & 17.00 & 37.44 & 36.99 & 13.73 \\
\hline $\mathrm{TS}(\% \mathrm{FM})^{1}$ & 74.81 & 83.00 & 62.56 & 63.01 & 86.27 \\
\hline VS (\% TS) ${ }^{1}$ & 49.67 & 26.10 & 60.01 & 70.09 & 45.10 \\
\hline TKN $\left(\mathrm{g} \mathrm{kg} \mathrm{TS}^{-1}\right)^{1}$ & 17.15 & 7.05 & 15.98 & 16.82 & 23.18 \\
\hline TAN $\left(\mathrm{g} \mathrm{kg} \mathrm{TS}^{-1}\right)^{1}$ & 0.50 & 1.19 & 5.56 & 2.84 & 0.47 \\
\hline $\mathrm{TP}\left(\mathrm{g} \mathrm{kg} \mathrm{TS}^{-1}\right)^{1}$ & 2.05 & 2.17 & 1.47 & 2.30 & 2.20 \\
\hline $\mathrm{TK}\left(\mathrm{g} \mathrm{kg} \mathrm{TS}^{-1}\right)^{1}$ & 6.79 & 5.18 & 2.58 & 3.20 & 1.60 \\
\hline $\mathrm{Cd}\left(\mathrm{mg} \mathrm{kg} \mathrm{TS}^{-1}\right)^{1}$ & 0.53 & 0.00 & 0.00 & 0.00 & 0.00 \\
\hline $\mathrm{Cr}\left(\mathrm{mg} \mathrm{kg} \mathrm{TS}^{-1}\right)$ & $23.77^{1}$ & $1596.39^{1}$ & $95.91^{2}$ & $31.74^{2}$ & $57.96^{1}$ \\
\hline $\mathrm{Cu}\left(\mathrm{mg} \mathrm{kg} \mathrm{TS}^{-1}\right)^{1}$ & 123.98 & 566.27 & 378.30 & 7279.27 & 367.06 \\
\hline $\mathrm{Ni}\left(\mathrm{mg} \mathrm{kg} \mathrm{TS}^{-1}\right)$ & $17.08^{1}$ & $698.80^{1}$ & $255.75^{2}$ & $31.74^{2}$ & $23.18^{2}$ \\
\hline $\mathrm{Pb}\left(\mathrm{mg} \mathrm{kg} \mathrm{TS}^{-1}\right)$ & $21.58^{1}$ & $131.33^{1}$ & $303.71^{2}$ & $63.48^{2}$ & $11.59^{2}$ \\
\hline $\mathrm{Zn}\left(\mathrm{mg} \mathrm{kg} \mathrm{TS}^{-1}\right)$ & $217.84^{1}$ & $638.55^{1}$ & $7885.76^{1}$ & $2920.17^{2}$ & $7519.03^{1}$ \\
\hline
\end{tabular}

${ }^{1}$ Mean of three determinations; ${ }^{2}$ Individual determination.

The moisture contents in the us-OFRMW from PT1, PT3, and PT5 (Table 2) resulted within the range of $40-57.85 \%$ FM derivable for mechanically sorted organic fractions of RMW from literature indications [42,43], while the moisture contents in the us-OFRMW from PT2 and PT4 (Table 2) were close to the lower limit of this range. The VS contents in the us-OFRMW from PT2, PT3, and PT5 (Table 2) were within the range of 47.15-65.9\% TS derivable for mechanically sorted organic fractions of RMW from literature indications [2,44], while the VS contents in the us-OFRMW from PT1 and PT4 were close to the lower limit of this range. The TKN contents in the us-OFRMW from PT2, PT3, and PT4 (Table 2) were within the range of 11.2-34 $\mathrm{g} \mathrm{kg} \mathrm{TS}^{-1}$ derivable for mechanically sorted organic fractions of RMW from literature indications [30,42], while the TKN contents in the us-OFRMW from PT1 and PT5 (Table 2) resulted below the lower limit of this range. Except for PT4, the TP contents in the us-OFRMW from the remaining provincial territories 
(Table 2) fell within the range of $0.5-2.2 \mathrm{~g} \mathrm{~kg} \mathrm{TS}^{-1}$ reported in the literature for the mechanically sorted organic fraction of RMW [30]. The resulting regional mean (equal to $3.79 \mathrm{~g}$ $\mathrm{kg} \mathrm{TS}^{-1}$ ) of the TK contents in the us-OFRMW from all the provincial territories (Table 2) was close to the value of $4.26 \mathrm{~g} \mathrm{~kg} \mathrm{TS}^{-1}$ obtained for a mechanically recovered organic fraction [31]. Finally, comparing the resulting heavy metal contents in Table 2 in each provincial territory, Zn showed the highest level in four provincial territories (PT1, PT2, PT4, PT5), while Cu presented the highest level in the remaining provincial territory (PT3).

Regarding the bios-OFRMW, the moisture contents from PT1-PT4 (Table 3) resulted within the range of $13.78-42.80 \%$ FM derivable for aerobically stabilised organic fractions of RMW from literature indications $[44,45]$, while the moisture content from PT5 (Table 3) remained practically at the lower limit of this range. The VS contents in the bios-OFRMW from PT1, PT3, and PT5 (Table 3) were within the range of 29.30-63.67\% TS derivable for aerobically stabilised organic fractions of RMW from literature indications [43,44], while the VS contents in the bios-OFRMW from PT2 and PT4 (Table 3) were close to the lower and upper limits of this range, respectively. The TKN contents in the bios-OFRMW from all the provincial territories (Table 3) fell within the range of $6.8-26 \mathrm{~g} \mathrm{~kg} \mathrm{TS}^{-1}$ for total nitrogen derivable for biologically stabilised organic fractions of RMW from literature indications $[46,47]$.

The TP contents in the bios-OFRMW from all the provincial territories (Table 3) were within the range of $0.9-3.77 \mathrm{~g} \mathrm{~kg} \mathrm{TS}^{-1}$ derivable for aerobically stabilised organic fractions of RMW from literature indications $[45,48]$. The TK contents in the bios-OFRMW from PT1-PT4 (Table 3) were within the range of $2.10-23.71 \mathrm{~g} \mathrm{~kg} \mathrm{TS}^{-1}$ derivable for aerobically stabilised organic fractions of RMW from literature indications [45,49], while the TK content in the bios-OFRMW from PT5 (Table 3) remained below the lower limit of this range. As found in the us-OFRMW, Zn showed in Table 3 the highest content among the analysed heavy metals in the prevailing number of provincial bios-OFRMW (from PT1, PT3, and PT5), while $\mathrm{Cr}$ and $\mathrm{Cu}$ presented in Table 3 the highest contents in the bios-OFRMW from PT2 and PT4, respectively. Indeed, comparative conditions with $\mathrm{Zn}, \mathrm{Cr}$, and Cu presenting the largest amounts among the detected heavy metals in aerobically stabilised organic fractions of RMW were similarly revealed in the literature $[46,50,51]$.

Interestingly, the direct comparison between the respective provincial us-OFRMW (Table 2) and bios-OFRMW (Table 3) revealed mutual decreases in the moisture content: on the regional average, the relative reduction (calculated as [ moisture $_{\text {us-OFRMW }}-$ moisture $_{\text {bios-OFRMW }}$ )/(moisture us-OFRMW $_{\text {) }}$ * 100]) was equal to 38\% (given the resulting regional mean moistures of 41.99 and $26.07 \%$ FM, respectively). In general, decreases in moisture and VS contents could be indicative of progress in a typical aerobic biodegradation process $[10,52]$. Concerning the VS content, mutual decreases between us-OFRMW (Table 2) and bios-OFRMW (Table 3) appeared for PT3, PT5, and PT2, with resulting relative reductions (calculated as $\left.\left[\left(\mathrm{VS}_{\mathrm{us}-\mathrm{OFRMW}}-\mathrm{VS}_{\text {bios-OFRMW }}\right) /\left(\mathrm{VS}_{\mathrm{us}-\mathrm{OFRMW}}\right)\right] * 100\right)$ equal to 2 , 19 , and $47 \%$, respectively. Indeed, the influence of heterogeneity in materials such as the mechanically separated OFRMW should be considered $[2,43,46]$. In particular, the presence of non- (i.e., plastic and rubber) or not readily (i.e., paper/cardboard) biodegradable volatile matter, generally occurring in the mechanically separated OFRMW, may mask the actual biogenic VS reduction obtained by the aerobic biological treatment $[2,43,45,53]$. In this regard, it should be considered that plastic, diaper (which is expected to be primarily made of polymers, including cellulose, polypropylene, polyester, and polyethylene [54]), and paper/cardboard fractions presented, on average, relevant incidences in the RMW of the Marche Region (see Section 3.2 and Figure 5f): even individually in PT4, diaper represented the highest compositional level in the respective RMW (see Figure 5d). Moreover, the influence of the procedure (in this study) of sampling at the same time both the us-OFRMW and bios-OFRMW, rather than sampling the same input material along the biological step, could also be expected [46].

Based on the VS and TS contents in Tables 2 and 3 and the adopted experimental BMPs per VS unit (see Sections 2.4 and 2.5), the derived BMPs per FM unit for the us-OFRMW 
and bios-OFRMW from each provincial territory are reported in Table 4. As shown in Table 4, the us-OFRMW from each provincial territory presented a higher BMP than the respective bios-OFRMW; the resulting relative differences (calculated as [ $\left(\mathrm{BMP}_{\mathrm{us}-\mathrm{OFRMW}}-\right.$ $\left.\left.\left.\mathrm{BMP}_{\text {bios-OFRMW }}\right) /\left(\mathrm{BMP}_{\text {us-OFRMW }}\right)\right] * 100\right)$ ranged from $45 \%$ in PT4 to $78 \%$ in PT2. Finally, based on the respective provincial values in Table 4, the resulting regional means of 131.1 $\mathrm{Nm}^{3} \mathrm{CH}_{4}$ ton $\mathrm{FM}^{-1}$ for us-OFRMW and $51.5 \mathrm{Nm}^{3} \mathrm{CH}_{4}$ ton $\mathrm{FM}^{-1}$ for bios-OFRMW constituted the representative BMPs in the elaboration of the future time basis of the BIOENERGY $_{\text {us-OFRMW }}$ and BIOENERGY-IMPACT bios-OFRMW $_{\text {scenarios, respectively (see }}$ Sections 2.4 and 2.5).

Table 4. Derived BMPs per FM unit for the us-OFRMW and bios-OFRMW from each provincial territory in the Marche Region.

\begin{tabular}{|c|c|c|}
\hline \multirow{2}{*}{ Provincial Territory } & \multicolumn{2}{|c|}{$\begin{array}{c}\text { BMP } \\
{\left[\mathrm{Nm}^{3} \mathrm{CH}_{4} \text { ton } \mathrm{FM}^{-1}\right]}\end{array}$} \\
\hline & us-OFRMW & bios-OFRMW \\
\hline PT1 & 118.4 & 53.3 \\
\hline PT2 & 140.3 & 31.1 \\
\hline PT3 & 159.9 & 53.8 \\
\hline PT4 & 115.2 & 63.3 \\
\hline PT5 & 121.8 & 55.8 \\
\hline
\end{tabular}

\subsection{Resulting BIOENERGY $Y_{\text {us-OFRMW }}$ Scenario}

Table 5 shows the resulting amounts of the us-OFRMW and the related potential bioenergy recovery in the provincial territories of the Marche Region at the present time basis (reference year 2019). At the whole regional level, the production of the us-OFRMW amounts to about 70,000 ton year ${ }^{-1}$ (Table 5). In the Marche Region, the alternative anaerobic biological treatment of the us-OFRMW would provide $4.35 \mathrm{MW}_{\mathrm{el}}$ of electrical power, a gross and net electrical energy production of 35.68 and $32.28 \mathrm{GWh}_{\text {year }}{ }^{-1}$, respectively, and a gross CHP energy recovery of 77.46 GWh year ${ }^{-1}$ (Table 5).

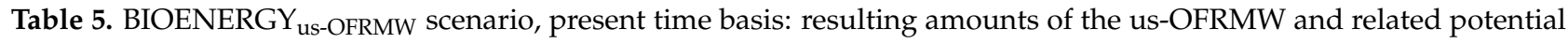
bioenergy recovery through $\mathrm{AD}$ in the provincial territories and the whole Marche Region.

\begin{tabular}{|c|c|c|c|c|c|c|}
\hline $\begin{array}{c}\text { Provincial Territory/ } \\
\text { Total }\end{array}$ & $\begin{array}{l}\text { us-OFRMW } \\
\text { (ton year }^{-1} \text { ) }\end{array}$ & $\begin{array}{l}\text { Biomethane } \\
\text { Production } \\
\left(\mathrm{Nm}^{3} \text { year }^{-1}\right)\end{array}$ & $\begin{array}{c}\text { Gross Electrical } \\
\text { Energy } \\
\text { (GWh year }^{-1} \text { ) }\end{array}$ & $\begin{array}{c}\text { Electrical Power } \\
\left(\mathrm{MW}_{\mathrm{el}}\right)\end{array}$ & $\begin{array}{c}\text { Net Electrical } \\
\text { Energy } \\
\text { (GWh year } \\
\text { (G) }\end{array}$ & $\begin{array}{c}\text { Gross CHP } \\
\text { Energy Recovery } \\
\left(\text { GWh year }^{-1}\right)\end{array}$ \\
\hline PT1 & 11,268 & $1,334,160$ & 5.07 & 0.62 & 4.59 & 11.01 \\
\hline PT2 & 25,997 & $3,647,362$ & 13.86 & 1.69 & 12.54 & 30.09 \\
\hline PT3 & 12,159 & $1,943,819$ & 7.39 & 0.90 & 6.68 & 16.04 \\
\hline PT4 & 7822 & 901,132 & 3.42 & 0.42 & 3.10 & 7.43 \\
\hline PT5 & 12,826 & $1,562,152$ & 5.94 & 0.72 & 5.37 & 12.89 \\
\hline Marche Region & 70,072 & $9,388,625$ & 35.68 & 4.35 & 32.28 & 77.46 \\
\hline
\end{tabular}

Interestingly, by comparing (Table 6) the potential bioenergy recovery through $\mathrm{AD}$ from the us-OFRMW to representative electrical energy production sources in the Marche Region [55], there would be a positive contribution of $1.8 \%$ and, particularly, $24.4 \%$ on the gross electrical energy productions from renewable sources and bioenergy, respectively; moreover, the positive contribution on the regional gross thermoelectric (CHP) energy production would be equal to $8.0 \%$. The further comparison of the expected regional net electrical energy production from the us-OFRMW to electrical energy consumptions by representative regional sectors [55] reveals, in Table 6, alternative shares ranging from $1.3 \%$ in the manufacturing industry to $30.8 \%$ in the public offices. 


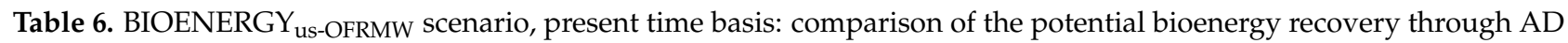
from the us-OFRMW to electrical energy productions and consumptions in the Marche Region.

\begin{tabular}{|c|c|}
\hline Comparison to Energy Production or Consumption & us-OFRMW \\
\hline \multicolumn{2}{|c|}{ Contributions on regional electrical energy production sources [55] } \\
\hline \multicolumn{2}{|l|}{ Gross electrical energy (see Table 5) on: } \\
\hline - regional gross electrical energy production from renewable sources (\%) & 1.8 \\
\hline - regional gross electrical energy production from bioenergy $(\%)$ & 24.4 \\
\hline Gross CHP energy recovery (see Table 5) on regional gross CHP energy production (\%) & 8.0 \\
\hline \multicolumn{2}{|c|}{ Alternative shares in regional electrical energy consumptions by representative sectors [55] } \\
\hline Net electrical energy (see Table 5) in: & \\
\hline - regional electrical energy consumption by agriculture (\%) & 28.5 \\
\hline - regional electrical energy consumption by manufacturing industry (\%) & 1.3 \\
\hline - regional electrical energy consumption by commercial sector $(\%)$ & 5.7 \\
\hline - regional electrical energy consumption by public offices $(\%)$ & 30.8 \\
\hline - regional electrical energy consumption by health service (\%) & 26.3 \\
\hline - regional electrical energy consumption by public lighting (\%) & 19.1 \\
\hline - regional electrical energy consumption by hospitality sector (\%) & 10.1 \\
\hline - regional electrical energy consumption by domestic sector $(\%)$ & 2.1 \\
\hline
\end{tabular}

As shown in Table 5, the resulting electrical powers in four provincial territories (PT1PT3 and PT5) refer to the capacity category of large-scale biogas plants ( $\geq 500 \mathrm{~kW}_{\mathrm{el}}$ [23]), while the resulting electrical power in the remaining provincial territory (PT4) falls within the capacity category of small-scale biogas plants $\left(<500 \mathrm{~kW}_{\mathrm{el}}\right.$ [23]). For the present time basis, a reasoned location of the potential AD lines for the bioenergy recovery from the us-OFRMW was assessed based on two alternative approaches. In the first approach displayed in the left map (a) of Figure 6, all the provincial territories were maintained as the zones of influence for MW management; then, the AD lines were properly placed in areas already designed for MW treatment (which for PT1 is indicatively set in one of the coastal districts). Instead, the second approach aimed at reaching an overall economy of scale (in terms of expected capital and operation costs [56]) by implementing solely large-scale AD lines. In particular, as displayed in the right map (b) of Figure 6, the provincial territory PT4 was properly grouped with the adjoining provincial territory PT5; then, for this combined zone of influence, the single AD line (with a cumulative electrical power of $1.14 \mathrm{MW}_{\mathrm{el}}$ ) may be located alternatively in one of the two provincial territories.

In accordance with the complementary evaluation (see Figure 3, left-down) at the present time basis, if the provincial sc-OFMW streams were also treated through $\mathrm{AD}$, the aggregation of the potential bioenergy recovery from both the us-OFRMW (see Table 5) and sc-OFMW (Table S3 of the Supplementary Material) would raise the overall regional performances (in terms of electrical power, gross and net electrical energy, and gross $\mathrm{CHP}$ energy recovery) to the respective levels displayed in Table S4 of the Supplementary Material. Consequently, as shown in Table S5 of the Supplementary Material, the overall positive contributions on the regional gross electrical energy productions from renewable sources and bioenergy [55] would raise to $6.0 \%$ and even $79.6 \%$, respectively; moreover, the overall positive contribution on the regional gross CHP energy production [55] would raise to $26.2 \%$. As further shown in Table S5 of the Supplementary Material, the overall net electrical energy production from both the us-OFRMW and sc-OFMW would raise the resulting shares in regional energy consumptions [55] to the increased range from $4.3 \%$ in the manufacturing industry to full coverage in the public offices. 


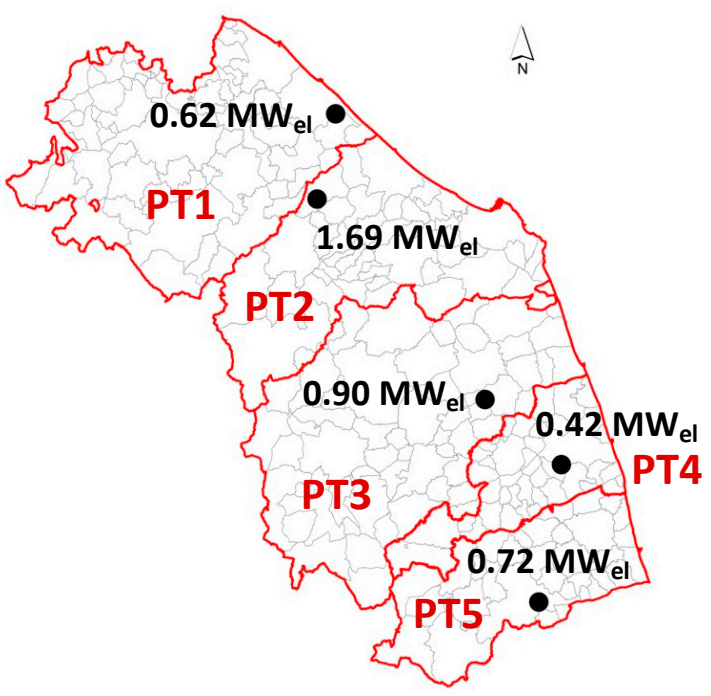

(a)

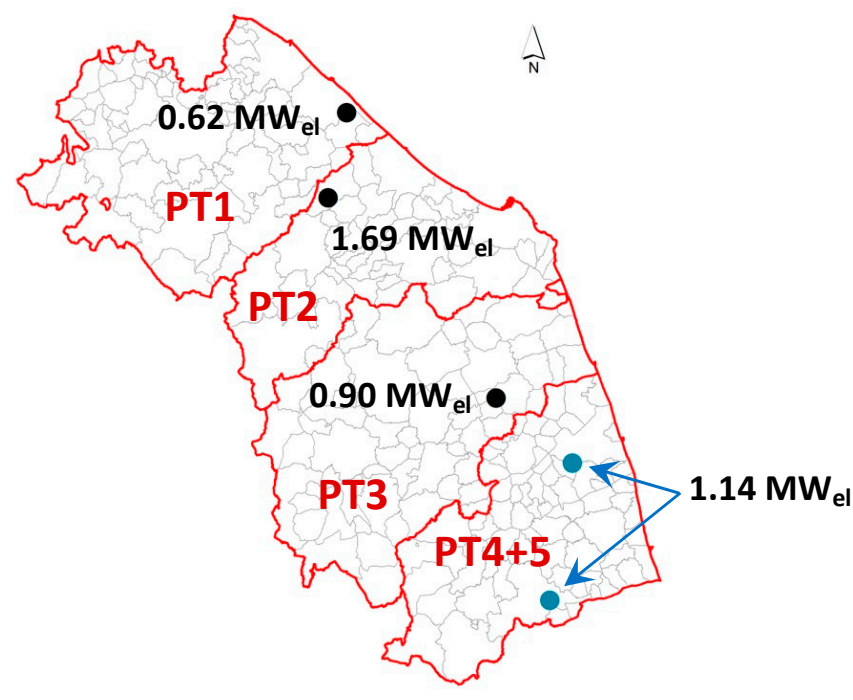

(b)

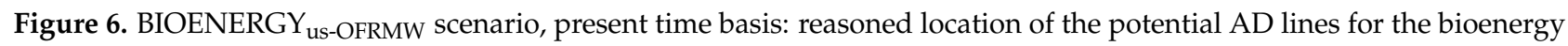
recovery from the us-OFRMW in the Marche Region in accordance with (a) the maintenance of all the provincial zones for MW management and (b) an overall economy of scale.

In the future time basis (reference year 2035), the combination of the assumed containment of regional population and per capita MW generation (see Sections 2.1 and 2.4) and a certain increase in the level of sc-MW (estimated to be equal to $74.6 \%$ based on the strong fit with the modified Gompertz modelling displayed in Figure S2 of the Supplementary Material, with a resulting high value of the $R^{2}$ —coefficient of determination—of 0.990 [41]) would reduce the estimated regional amount of the us-OFRMW (shown in Table 7) as compared with the generated amount in the present year 2019 (see Table 5). Consequently, the estimated regional performances of the potential bioenergy recovery through $\mathrm{AD}$ from the us-OFRMW in the future year 2035, shown in Table 7 in terms of electrical power, gross and net electrical energy, and gross CHP energy recovery, would be reduced compared with the respective levels in the present year 2019 (see Table 5), with resulting individual relative decreases (calculated as [(performance 2019 - performance 2035$) /\left(\right.$ performance $\left.\left.\left._{2019}\right)\right] * 100\right)$ equal to $20.2 \%$. Indeed, as shown in Table 7 , a regional electrical power of $3.47 \mathrm{MW}_{\mathrm{el}}$ would still be provided in 2035, which ideally corresponds to zonal means of 0.69 and $0.87 \mathrm{MW}_{\mathrm{el}}$ related to the maintenance of the provincial zones of MW management (Figure 6a) or to the optimised zones (Figure $6 \mathrm{~b}$ ), respectively. Both average conditions fall within the category of large-scale biogas plants $\left(\geq 500 \mathrm{~kW}_{\mathrm{el}}[23]\right)$.

Table 7. BIOENERGY us-OFRMW scenario, future time basis: estimated amount of the us-OFRMW and related potential bioenergy recovery through $\mathrm{AD}$ in the whole Marche Region.

\begin{tabular}{cc}
\hline & us-OFRMW \\
\hline Amount (ton year & \\
\hline Biomethane production $\left(\mathrm{Nm}^{3}\right.$ year $\left.^{-1}\right)$ & 57,132 \\
Gross electrical energy $\left(\mathrm{GWh} \mathrm{year}^{-1}\right)$ & $7,490,751$ \\
Electrical power $\left(\mathrm{MW}_{\mathrm{el}}\right)$ & 28.46 \\
Net electrical energy $\left(\mathrm{GWh}_{\text {year }}{ }^{-1}\right)$ & 3.47 \\
Gross CHP energy recovery $\left(\mathrm{GWh}^{-1}\right.$ year & 25.76 \\
\hline
\end{tabular}

In the complementary evaluation at the future time basis, due to the estimated increase in the level of sc-MW, the expected regional performances of the potential bioenergy recovery through AD from the sc-OFMW, shown in Table S6 of the Supplementary Ma- 
terial in terms of electrical power, gross and net electrical energy, and gross CHP energy recovery, would present individual relative decreases limited to $5.9 \%$ compared with the present year 2019 (see Table S3 of the Supplementary Material). Finally, the overall regional performances in 2035, expected from the aggregation of the potential bioenergy recovery from both the us-OFRMW and sc-OFMW, are provided in Table S7 of the Supplementary Material.

\subsection{Resulting BIOENERGY-IMPACT bios-OFRMW $_{\text {Scenario }}$}

Table 8 shows the resulting amounts of the bios-OFRMW and the related proportions of overall bioenergy recovery and impact as GHG diffuse emissions from the deposited bios-OFRMW in the provincial territories of the Marche Region at the present time basis (reference year 2019). At the whole regional level (Table 8), the bios-OFRMW amounts to about 51,600 ton year $^{-1}$, with an expected overall bioenergy recovery as gross electrical energy (during the landfill lifetime) limited to $7.07 \mathrm{GWh}$; concurrently, the overall impact in terms of landfill GHG diffuse emissions would consist in about 10,000 ton $\mathrm{CO}_{2}$ eq., resulting in $195 \mathrm{~kg} \mathrm{CO} 2$ eq. per ton of deposited bios-OFRMW.

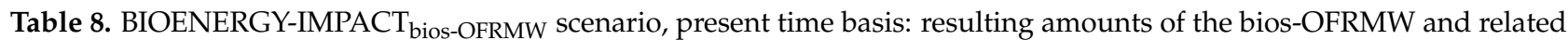
proportions of overall bioenergy recovery and impact as GHG diffuse emissions from the deposited bios-OFRMW in the provincial territories and the whole Marche Region.

\begin{tabular}{ccccc}
\hline $\begin{array}{c}\text { Provincial } \\
\text { Territory/Total }\end{array}$ & $\begin{array}{c}\text { bios-OFRMW } \\
\text { (ton year }\end{array}$ & $\begin{array}{c}\text {-1) } \\
\text { Biomethane Generation } \\
\mathbf{( N m}^{\mathbf{3}} \mathbf{)}\end{array}$ & $\begin{array}{c}\text { Overall Bioenergy as } \\
\text { Gross Electrical Energy } \\
\text { (GWh) }\end{array}$ & $\begin{array}{c}\text { Overall Impact as GHG } \\
\text { Diffuse Emissions } \\
\text { (ton } \mathbf{C O}_{\mathbf{2}} \text { eq.) }\end{array}$ \\
\hline PT1 & 6843 & 364,746 & 1.07 & 1522 \\
PT2 & 19,480 & 605,838 & 1.78 & 2527 \\
PT3 & 9995 & 537,708 & 1.57 & 2243 \\
PT4 & 6183 & 391,354 & 1.15 & 1633 \\
PT5 & 9161 & 511,190 & 1.50 & 2133 \\
\hline Marche Region & 51,662 & $2,410,836$ & 7.07 & 10,058 \\
\hline
\end{tabular}

${ }^{1}$ Total (cumulative) production from the yearly deposited bios-OFRMW that is expected to be approached exponentially during the landfill lifetime.

In the future time basis (reference year 2035), the combination of the assumed containment of regional population and per capita MW generation (see Sections 2.1 and 2.4) and a certain increase in the level of sc-MW (see Section 3.4) would reduce the estimated regional amount of the bios-OFRMW to be deposited (shown in Table 9) as compared with the resulting amount at the present year 2019 (see Table 8). Consequently, the estimated overall bioenergy recovery and impact as GHG diffuse emissions, shown in Table 9, would be lower compared with the respective levels at the present year 2019 (see Table 8), with resulting individual relative decreases (calculated as [(bioenergy/impact 2019 - bioenergy/impact 2035 )/ (bioenergy/impact 2019$)] * 100$ ) limited to about $9 \%$.

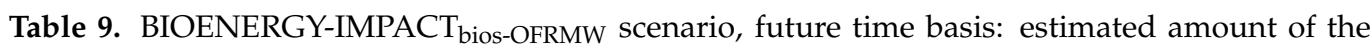
bios-OFRMW and related proportions of overall bioenergy recovery and impact as GHG diffuse emissions from the deposited bios-OFRMW in the whole Marche Region.

\begin{tabular}{cc}
\hline & bios-OFRMW \\
\hline Amount (ton year $\left.{ }^{-1}\right)$ & 42,451 \\
Residual landfill biomethane generation $\left(\mathrm{Nm}^{3}\right)^{1}$ & $2,184,514$ \\
Overall bioenergy as gross electrical energy $(\mathrm{GWh})$ & 6.40 \\
Overall impact as GHG diffuse emissions (ton $\mathrm{CO}_{2}$ eq.) & 9113 \\
\hline
\end{tabular}




\section{Discussion}

The physico-chemical characteristics (in terms of moisture, VS, TKN, TP, TK) of the investigated us-OFRMW and bios-OFRMW from the provincial territories in the Marche Region were mostly in line with or close to the literature data on the mechanically sorted and aerobically stabilised organic fractions of RMW, respectively (see Tables 2 and 3 and Section 3.3). Similarly, the resulting partitions in terms of the largest contents of heavy metals in the investigated bios-OFRMW were noticed in the literature for aerobically stabilised organic fractions of RMW (see Table 3 and Section 3.3). Thus, the studied provincial MBT systems in the Marche Region appeared to be representative examples of the aerobic biostabilisation variation of the MBT concept.

Interestingly, the elaboration and comparative evaluation of the mass balances for the provincial MBT systems in the Marche Region revealed the influence of sieving size (and, eventually, also of optimised shredding) in the MT step on the resulting quantitative partition between the os-RMW and the targeted us-OFRMW (see Figure 4 and Section 3.1). At the reference year 2035 of the future time basis, the assumed regional mean of $32.3 \%$ as the mass balance level for the us-OFRMW (see Table 1 and Section 3.1) would be close to the regional level of $30.8 \%$ for the overall organic component in the RMW (see Figure $5 f$ and Section 3.2). This resulting condition of similar levels reflects the desirable effort in the coming years to harmonise and optimise the MT steps in the provincial MBT systems of the Marche Region in order to perform an effective separation of the organic fraction in the undersize streams.

At the present time (reference year 2019), the potential diversion of the us-OFRMW to alternative $\mathrm{AD}$ steps within the regional MBT concept, in accordance with the application

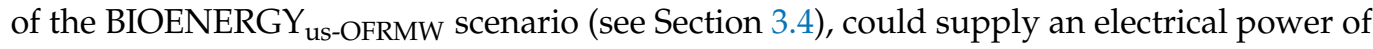
$4.35 \mathrm{MW}_{\mathrm{el}}$ in the whole Marche Region (see Table 5), thus representing a renewable option of net electrical energy production (see Table 5) potentially available to contribute to cover electrical energy consumptions by representative regional sectors (see Table 6). Eventually, a limited reorganisation of the existing zones of influence for MW management in the Marche Region (see Figure 6b) could allow for the implementation of related AD lines that would result in the favourable capacity category of large-scale biogas plants. On the contrary, if the current RMW management in the Marche Region continues to be applied, in

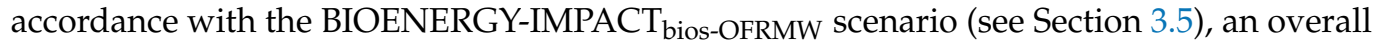
impact of about 10,000 ton $\mathrm{CO}_{2}$ eq. as GHG diffuse emissions during the lifetime of landfills is expected from the regional bios-OFRMW deposited at the present year, 2019 (see Table 8). Moreover, the concurrent overall gross electrical energy of 7.07 GWh, which is expected during the lifetime of landfills from the bioenergy recovery of the regional bios-OFRMW deposited in 2019 (see Table 8 ), would represent a limited share (19.8\%) of the yearly gross electrical energy of $35.68 \mathrm{GWh}_{\text {year }}{ }^{-1}$ from the alternative valorisation through $\mathrm{AD}$ of the us-OFRMW (see Table 5). This resulting comparative condition points out two relevant and linked aspects: (1) the intrinsically contained bioenergy potential of a biostabilised organic residue (as the bios-OFRMW) compared with the initial untreated organic residue (as the us-OFRMW) [10], which is mathematically confirmed in this study by the resulting relative differences in the respective BMPs of Table 4 (see Section 3.3); and (2) the different temporal scales generally expected to reach a similar degree of biodegradation in landfills (decades) compared with AD plants (days) [57,58].

At the future time (reference year 2035), a reduction in the potential bioenergy recovery through AD from the us-OFRMW would be expected in the whole Marche Region due to reasonable assumptions on the containment of regional population and per capita MW generation and a moderate increase of the regional level of sc-MW (see Section 2.4 and Figure S2 of the Supplementary Material): nevertheless, an electrical power of $3.47 \mathrm{MW}_{\mathrm{el}}$ could still be guaranteed (see Table 7). On the long-term scale (from 2019 to 2035) considered in this study, the expected total beneficial effects of implementing the bioenergy recovery through AD from the us-OFRMW in the Marche Region are clearly shown in Table S8 of the Supplementary Material. 
With a synergic MW management approach in the Marche Region, the potential bioenergy recovery through $\mathrm{AD}$ from the us-OFRMW could be complementarily integrated by a similar anaerobic biological treatment of the sc-OFMW in regional facilities (see Tables S3, S4, S6 and S7 of the Supplementary Material). The resulting aggregation of the expected net electrical energy productions from the potential bioenergy recovery of both organic streams would considerably increase the overall contribution to cover electrical energy consumptions by representative sectors in the Marche Region at the considered present time basis (see Table S5 of the Supplementary Material).

Finally, the feasibility of implementing an AD step within a biostabilisation MBT system is indicated by some full-scale MBT facilities including AD, documented in the literature, with operative locations in France [59,60], Germany [61], Poland [62], Spain [45,59], and the UK $[63,64]$. Moreover, a similar interest in implementing an MBT scheme including $\mathrm{AD}$ is documented in the literature for a municipal case-study area in another Mediterranean country, such as Greece [65].

\section{Conclusions}

Two alternative scenarios were elaborated and evaluated in this study to investigate the management of the organic fraction of RMW in the Marche Region (Central Italy) on a long-term period (from the present time basis in 2019 to the future time basis in 2035).

Possible developments of this study could cover the extension of experimental BMP tests to the us-OFRMW and bios-OFRMW from all the provincial territories in the Marche Region, together with additional organic residues of interest at the regional level (including the components of the complementary sc-OFMW from all the provincial territories). Finally, the overall data obtained in the study could be properly exploited through a life cycle assessment.

Supplementary Materials: The following are available online at https:/ /www.mdpi.com/article/ 10.3390/su132011462/s1, Figure S1: Synthetic representation of the overall MW management in the Marche Region. Table S1: Representative characteristics of the aerobic biostabilisation MBT systems located in the Marche Region. Table S2: Sequential procedure adopted to conduct the compositional analyses of the RMW streams addressed to the provincial aerobic biostabilisation MBT systems in the

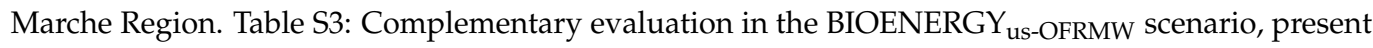
time basis: resulting amounts of the sc-OFMW and related potential bioenergy recovery through $\mathrm{AD}$ in the provincial territories and the whole Marche Region. Table S4: Complementary evaluation

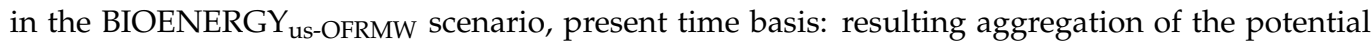
bioenergy recovery through AD from the us-OFRMW (see Table 5) and sc-OFMW (see Table S3) in the whole Marche Region. Table S5: Complementary evaluation in the BIOENERGY ${ }_{\text {us-OFRMW scenario, }}$ present time basis: comparison of the aggregation of the potential bioenergy recovery through $\mathrm{AD}$ from the us-OFRMW and sc-OFMW to electrical energy productions and consumptions in the

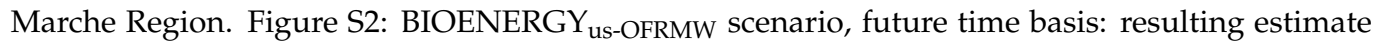
of the level of sc-MW in the reference year 2035 based on the modified Gompertz modelling (see

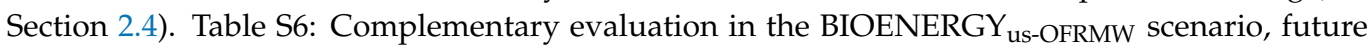
time basis: estimated amount of the sc-OFMW and related potential bioenergy recovery through $\mathrm{AD}$ in the whole Marche Region. Table S7: Complementary evaluation in the BIOENERGY ${ }_{\text {us-OFRMW }}$ scenario, future time basis: resulting aggregation of the potential bioenergy recovery through $\mathrm{AD}$ from the us-OFRMW (see Table 7) and sc-OFMW (see Table S6) in the whole Marche Region. Table S8: BIOENERGY ${ }_{\text {us-OFRMW versus BIOENERGY-IMPACT }}$ bios-OFRMW scenario: expected beneficial effects of the potential bioenergy recovery through AD from the us-OFRMW on the long-term scale (from 2019 to 2035) in the whole Marche Region.

Author Contributions: Conceptualisation, F.T. and M.B.; methodology, M.B., M.D.A., A.F. and F.T.; validation, M.B., M.D.A., A.F. and F.T.; formal analysis, M.D.A., A.F. and F.T.; investigation, M.B., M.D.A., A.F. and F.T.; resources, M.B. and F.T.; data curation, M.B., M.D.A., A.F. and F.T.; writingoriginal draft preparation, M.D.A., A.F. and F.T.; writing-review and editing, F.T.; visualisation, M.B., M.D.A., A.F. and F.T.; supervision, F.T.; project administration, F.T.; funding acquisition, F.T. All authors have read and agreed to the published version of the manuscript. 
Funding: This study was partly supported by the Department of Pure and Applied Sciences (DiSPeA) at the University of Urbino "Carlo Bo", based on the co-funded Project "BO-ASET Marche, Biological Organic Anaerobic System for Energy Technologies: Scenarios of Biomethanation from the Residual Municipal Waste in the Marche Region" (DISPEA_PROG19) (in Italian) within the departmental "Call for Proposals 2019".

Institutional Review Board Statement: Not applicable.

Informed Consent Statement: Not applicable.

Data Availability Statement: The data presented in this study are available on request from the corresponding author.

Acknowledgments: The authors are grateful to E. Tatani, final-year student in Geological and Environmental Sciences at the University of Urbino "Carlo Bo", for his contribution in performing compositional analyses. The authors thank S. de Rosa and A. Giuliani (at the ASET), S. Dominici, R. Testalunga, and D. Ugolini (at the Marche Multiservizi), D. Bertolacci, M. Stella, and S. Ulissi (at the CIR33), M. Procaccini (at the COSMARI), P. Marconi, S. Nicolini, and V. Vitali (at the Asite), and S. Benigni and R. Leli (at the PicenAmbiente) for their assistance in sampling the waste materials and providing useful information on the respective provincial MBT systems. A. Di Paolo and A. Berloni at the Environmental Science Laboratory of the University of Urbino "Carlo Bo" are mentioned for their support in conducting analytical characterisations.

Conflicts of Interest: The authors declare no conflict of interest.

\section{References}

1. ISPRA (Italian Institute for Environmental Protection and Research). Municipal Waste Report-Edition 2020; Report Series No. 331/2020; ISPRA: Rome, Italy, 2020. (In Italian)

2. Di Lonardo, M.C.; Lombardi, F.; Gavasci, R. Quality evaluation and improvement of mechanically-biologically treated municipal solid waste in view of a possible recovery. Int. J. Environ. Sci. Technol. 2015, 12, 3243-3254. [CrossRef]

3. Christensen, T.H.; Manfredi, S.; Kjeldsen, P. Landfilling: Environmental issues. In Solid Waste Technology E Management; Christensen, T.H., Ed.; John Wiley \& Sons Ltd.: Chichester, UK, 2010; Volume 2, pp. 695-708.

4. Stegmann, R. Landfilling: MBP waste landfills. In Solid Waste Technology \& Management; Christensen, T.H., Ed.; John Wiley \& Sons Ltd.: Chichester, UK, 2010; Volume 2, pp. 788-799.

5. Trulli, E.; Ferronato, N.; Torretta, V.; Piscitelli, M.; Masi, S.; Mancini, I. Sustainable mechanical biological treatment of solid waste in urbanized areas with low recycling rates. Waste Manag. 2018, 71, 556-564. [CrossRef]

6. APAT (Italian Environmental Protection Agency and Technical Services). Physico-Chemical Characterisation of Organic Outputs from Mechanical Biological Waste Treatment Plants; Report Series; APAT: Rome, Italy, 2007. (In Italian)

7. CITEC (Italian Committee on Complex Technology Plants). Guidelines for the Design, Realisation, and Management of Complex Technology Plants for Municipal Waste Disposal, 2nd ed.; Hyper Publisher: Venice, Italy, 2008.

8. Di Lonardo, M.C.; Lombardi, F.; Gavasci, R. Characterization of MBT plants input and outputs: A review. Rev. Environ. Sci. Bio/Technol. 2012, 11, 353-363. [CrossRef]

9. Pantini, S.; Verginelli, I.; Lombardi, F.; Scheutz, C.; Kjeldsen, P. Assessment of biogas production from MBT waste under different operating conditions. Waste Manag. 2015, 43, 37-49. [CrossRef] [PubMed]

10. Carchesio, M.; Di Addario, M.; Tatàno, F.; de Rosa, S.; Gambioli, A. Evaluation of the biochemical methane potential of residual organic fraction and mechanically-biologically treated organic outputs intended for landfilling. Waste Manag. 2020, 113, 20-31. [CrossRef] [PubMed]

11. Capaccioni, B.; Caramiello, C.; Tatàno, F.; Viscione, A. Effects of a temporary HDPE cover on landfill gas emissions: Multiyear evaluation with the static chamber approach at an Italian landfill. Waste Manag. 2011, 31, 956-965. [CrossRef]

12. Di Maria, F. Upgrading of a mechanical biological treatment plant with a solid anaerobic digestion batch: A real case study. Waste Manag. Res. 2012, 30, 1089-1094. [CrossRef] [PubMed]

13. EEA (European Environment Agency). Bio-waste in Europe-turning challenges into opportunities, EEA Report no. 04/2020; Publications Office of the European Union: Luxembourg, 2020.

14. Carchesio, M.; Tatàno, F.; Lancellotti, I.; Taurino, R.; Colombo, E.; Barbieri, L. Comparison of biomethane production and digestate characterization for selected agricultural substrates in Italy. Environ. Technol. 2014, 35, 2212-2226. [CrossRef]

15. ARPAM (Environmental Protection Agency of the Marche Region). Annual Report on Municipal Waste in the Marche Region. 2019; Boccarossa, M., Ed.; ARPAM: Pesaro, Italy, 2020. (In Italian)

16. ISTAT (Italian National Institute of Statistics). The Extensions of Italian Municipalities, Provinces, and Regions; Report; ISTAT: Rome, Italy, 2013. (In Italian)

17. European Commission. Commission Decision of 18 December 2014 amending Decision 2000/532/EC on the list of waste pursuant to Directive 2008/98/EC of the European Parliament and of the Council. Off. J. Eur. Union 2014, 370, 44-86. 
18. ARPAM. Compositional Analyses of the RMW from the Provincial Districts in the Marche Region. 2017-2018; Boccarossa, M., Ed.; ARPAM: Pesaro, Italy, 2019. (In Italian)

19. Di Maria, F.; Sordi, A.; Micale, C. Energy production from mechanical biological treatment and composting plants exploiting solid anaerobic digestion batch: An Italian case study. Energy Convers. Manage. 2012, 56, 112-120. [CrossRef]

20. Marigo, L.; Pasqualin, P. Planning of biogas plants. In Biomethane from Biogas; Arecco, F., Ghelardi, G.P., Eds.; Edizioni Ambiente Publisher: Milan, Italy, 2018; pp. 57-67. (In Italian)

21. Torregrossa, M. Techniques for upgrade of biogas to biomethane. In Advanced Biological Treatments-BioMAc 2018; Series in Environmental Engineering; Belgiorno, V., Cesaro, A., Naddeo, V., Zarra, T., Eds.; ASTER Publisher: Fisciano, SA, Italy, 2018; pp. 315-336. (In Italian)

22. CRPA (Research Centre on Animal Production). Biogas: Technical and Economic Feasibility; Booklet Series No. 4/2008; CRPA: Reggio Emilia, Italy, 2008. (In Italian)

23. Pöschl, M.; Ward, S.; Owende, P. Evaluation of energy efficiency of various biogas production and utilization pathways. Appl. Energy 2010, 87, 3305-3321. [CrossRef]

24. ANPA (Italian Environment Protection Agency). Anaerobic Treatment of Waste. Design and Operation; Handbook and Standard Series No. 13/2002; ANPA: Rome, Italy, 2002. (In Italian)

25. European Parliament and Council of the European Union. Directive (EU) 2018/851 of the European Parliament and of the Council of 30 May 2018 amending Directive 2008/98/EC on waste. Off. J. Eur. Union 2018, L 150, 109-140.

26. Marche Region. Regional Waste Management Plan. Off. Bull. Marche Region. 2015, XLVI-Annex No. 4, 1-1241. (In Italian)

27. ISTAT. Population Forecast-Years 2018-2065. Available online: http:/ / dati.istat.it/Index.aspx?DataSetCode=DCIS_PREVDEM1 (accessed on 1 March 2021). (In Italian).

28. Marche Region. Prevention, Production, and Management of Waste in the Marche Region. 2017; Report No. 9; Regione Marche and ARPAM: Ancona and Pesaro, Italy, 2018. (In Italian)

29. Zwietering, M.H.; Jongenburger, I.; Rombouts, F.M.; van't Riet, K. Modeling of the bacterial growth curve. Appl. Environ. Microbiol. 1990, 56, 1875-1881. [CrossRef]

30. Cecchi, F.; Traverso, P.; Pavan, P.; Bolzonella, D.; Innocenti, L. Characteristics of the OFMSW and behaviour of the anaerobic digestion process. In Biomethanization of the Organic Fraction of Municipal Solid Wastes; Mata-Alvarez, J., Ed.; IWA Publishing: London, UK, 2002; pp. 141-180.

31. Zhang, Y.; Banks, C.J.; Heaven, S. Anaerobic digestion of two biodegradable municipal waste streams. J. Environ. Manage. 2012, 104, 166-174. [CrossRef] [PubMed]

32. Dillah, D.D.; Panesar, B.; Gornto, M.; Dieleman, B.L. New and Improved Implementation of the First Order Model for Landfill Gas Generation or Collection. SCS Engineers. Available online: https:/ /www.scsengineers.com/scs-white-papers/new-andimproved-implementation-of-the-first-order-model-for-landfill-gas-generation-or-collection/ (accessed on 1 March 2021).

33. Oonk, H. Literature Review: Methane from Landfills. Methods to Quantify Generation, Oxidation and Emission; Final Report; Oonkay Innovations in Environmental Technology: Apeldoorn, The Netherlands, 2010.

34. Tatàno, F.; Viscione, A.; de Rosa, S.; Corigliano, G.; Capaccioni, B. Landfill Gas Emission Monitoring with the Static, Non-stationary Chamber Method: A Long-term (2005-2016) Study at an Italian Site. In Proceedings of the Sardinia 2017, Sixteenth International Waste Management and Landfill Symposium, S. Margherita di Pula, Cagliari, Italy, 2-6 October 2017; CISA Publisher: Padova, Italy, 2017; pp. 1-17.

35. Willumsen, H.; Barlaz, M.A. Landfilling: Gas production, extraction and utilization. In Solid Waste Technology E Management; Christensen, T.H., Ed.; John Wiley \& Sons Ltd.: Chichester, UK, 2010; Volume 2, pp. 841-857.

36. Myhre, G.; Shindell, D.; Bréon, F.M.; Collins, W.; Fuglestvedt, J.; Huang, J.; Koch, D.; Lamarque, J.F.; Lee, D.; Mendoza, B.; et al. Anthropogenic and natural radiative forcing. In Climate Change 2013: The Physical Science Basis, Contribution of Working Group I to the Fifth Assessment Report of the Intergovernmental Panel on Climate Change; Stocker, T.F., Qin, D., Plattner, G.K., Tignor, M., Allen, S.K., Boschung, J., Nauels, A., Xia, Y., Bex, V., Midgley, P.M., Eds.; Cambridge University Press: Cambridge, UK; New York, NY, USA, 2013; pp. 659-740.

37. IRSA (Italian Water Research Institute). Analytical Methods for Sludge: Physico-Chemical Parameters; IRSA Book Series no. 64; CNR (Italian National Research Council) Publisher: Rome, Italy, 1985. (In Italian)

38. UNI (Italian Institute for Standardisation). Characterisation of Waste-Digestion for Subsequent Determination of Aqua Regia Soluble Portion of Elements; Standard UNI EN 13657:2004; UNI Publisher: Milan, Italy, 2004. (In Italian)

39. UNI. Water Quality-Determination of Selected Elements by Inductively Coupled Plasma Optical Emission Spectrometry; Standard UNI EN ISO 11885:2009; UNI Publisher: Milan, Italy, 2009.

40. USEPA (US Environmental Protection Agency). Method 6020B: Inductively Coupled Plasma-Mass Spectrometry, SW-846, Revision 2; USEPA: Washington, DC, USA, 2014. Available online: https://www.epa.gov/sites/production/files/2015-12/documents/6020 b.pdf (accessed on 1 March 2021).

41. Hebel, J.R.; McCarter, R.J. A Study Guide to Epidemiology and Biostatistics; Jones \& Bartlett Learning: Burlington, VT, USA, 2012.

42. Cesaro, A.; Russo, L.; Farina, A.; Belgiorno, V. Organic fraction of municipal solid waste from mechanical selection: Biological stabilization and recovery options. Environ. Sci. Pollut. Res. 2016, 23, 1565-1575. [CrossRef] [PubMed]

43. APAT. Methods for the Assessment of Waste Biological Stability; Handbook Series on Instruments and Methods No. 25/2003; APAT: Rome, Italy, 2003. (In Italian) 
44. De Gioannis, G.; Muntoni, A.; Cappai, G.; Milia, S. Landfill gas generation after mechanical biological treatment of municipal solid waste. Estimation of gas generation rate constants. Waste Manag. 2009, 29, 1026-1034. [CrossRef] [PubMed]

45. Montejo, C.; Costa, C.; Márquez, M.C. Influence of input material and operational performance on the physical and chemical properties of MSW compost. J. Environ. Manag. 2015, 162, 240-249. [CrossRef]

46. van Praagh, M.; Heerenklage, J.; Smidt, E.; Modin, H.; Stegmann, R.; Persson, K.M. Potential emissions from two mechanicallybiologically pretreated (MBT) wastes. Waste Manag. 2009, 29, 859-868. [CrossRef] [PubMed]

47. Environment Agency. A Review of Human Health and Environmental Risks Associated with the Land Application of Mechanical-Biological Treatment Outputs; Science report SC030144/SR2; Environment Agency: Bristol, UK, 2009.

48. Farrell, M.; Jones, D.L. Use of composts in the remediation of heavy metal contaminated soil. J. Hazard. Mater. 2010, 175, 575-582. [CrossRef]

49. Almendro-Candel, M.B.; Navarro-Pedreño, J.; Jordán, M.M.; Gómez, I.; Meléndez-Pastor, I. Use of municipal solid waste compost to reclaim limestone quarries mine spoils as soil amendments: Effects on Cd and Ni. J. Geochem. Explor. 2014, 144, 363-366. [CrossRef]

50. Alvarenga, P.; Palma, P.; Gonçalves, A.P.; Fernandes, R.M.; Cunha-Queda, A.C.; Duarte, E.; Vallini, G. Evaluation of chemical and ecotoxicological characteristics of biodegradable organic residues for application to agricultural land. Environ. Int. 2007, 33, 505-513. [CrossRef]

51. Pantini, S.; Verginelli, I.; Lombardi, F. Analysis and modeling of metals release from MBT wastes through batch and up-flow column tests. Waste Manag. 2015, 38, 22-32. [CrossRef]

52. Tatàno, F.; Pagliaro, G.; Di Giovanni, P.; Floriani, E.; Mangani, F. Biowaste home composting: Experimental process monitoring and quality control. Waste Manag. 2015, 38, 72-85. [CrossRef] [PubMed]

53. Salati, S.; Scaglia, B.; Di Gregorio, A.; Carrera, A.; Adani, F. The use of the dynamic respiration index to predict the potential MSW-leachate impacts after short term mechanical biological treatment. Bioresour. Technol. 2013, 128, 351-358. [CrossRef] [PubMed]

54. Dey, S.; Kenneally, D.; Odio, M.; Hatzopoulos, I. Modern diaper performance: Construction, materials, and safety review. Int. J. Dermatol. 2016, 55 (Suppl. 1), 18-20. [CrossRef] [PubMed]

55. TERNA (Italian National Electricity Transmission Grid). Statistical Report 2019-Marche Region. Available online: https: //www.terna.it/it/sistema-elettrico/statistiche/evoluzione-mercato-elettrico (accessed on 1 March 2021). (In Italian).

56. Ragazzoni, A. Analysis of the Return from Biogas Plants in Accordance with the New Subsidies. Available online: http://www. crpa.it/media/documents/crpa_www /Convegni/20130314_BiogasBiometano_RA/Ragazzoni_RA_14-3-2013.pdf (accessed on 1 March 2021). (In Italian).

57. Bogner, J.; Lagerkvist, A. Organic Carbon Cycling in Landfills: Model for a Continuum Approach. In Proceedings of Sardinia 97, Sixth International Landfill Symposium; Christensen, T.H., Cossu, R., Stegmann, R., Eds.; CISA Publisher: Cagliari, Italy, 1997; Volume I, pp. 45-56.

58. Fischer, C.; Maurice, C.; Lagerkvist, A. Gas Emission from Landfills. An Overview of Issues and Research Needs; AFR-Report 264; Swedish Environmental Protection Agency: Stockholm, Sweden, 1999.

59. Colón, J.; Ponsá, S.; Álvarez, C.; Vinot, M.; Lafuente, F.J.; Gabriel, D.; Sánchez, A. Analysis of MSW full-scale facilities based on anaerobic digestion and/or composting using respiration indices as performance indicators. Bioresour. Technol. 2017, 236, 87-96. [CrossRef] [PubMed]

60. Cord'homme, C. Integrated Residual Municipal Waste Treatment Combining Material from Waste, Organic Recovery and Energy from Waste-Case Studies. In Short Abstract Collection, Proceedings of the 5th MatER Meeting and 6th International Conference on Final Sinks, Recovery and Final Sinks for an Effective Waste Management, Virtual Event, 7-9 June 2021; Politecnico di Milano: Milan, Italy, 2021 ; p. 58.

61. Vielhaber, B. Mechanical-biological treatment plant in Hanover, Germany-Experience in mechanical processing, anaerobic digestion and refuse derived fuel quality. In Waste Management-Waste-to-Energy; Thomé-Kozmiensky, K.J., Thiel, S., Eds.; TK Verlag Karl Thomé-Kozmiensky: Neureppin, Germany, 2015; Volume 5, pp. 387-398.

62. Seruga, P.; Krzywonos, M.; Wilk, M. Treatment of by-products generated from anaerobic digestion of municipal solid waste. Waste Biomass Valorization 2020, 11, 4933-4940. [CrossRef]

63. DEFRA (Department for Environment, Food \& Rural Affairs). Mechanical Biological Treatment of Municipal Solid Waste; DEFRA: London, UK, 2013.

64. Cook, E.; Wagland, S.; Coulon, F. Investigation into the non-biological outputs of mechanical-biological treatment facilities. Waste Manag. 2015, 46, 212-226. [CrossRef]

65. Thanopoulos, S.; Karellas, S.; Kavrakos, M.; Konstantellos, G.; Tzempelikos, D.; Kourkoumpas, D. Analysis of alternative MSW treatment technologies with the aim of energy recovery in the municipality of Vari-Voula-Vouliagmeni. Waste Biomass Valorization 2020, 11, 1585-1601. [CrossRef] 